\title{
$\angle$ Research Square \\ Design and Kinematic Analysis of a 4-SPS/U-based Four-level Rigid Trunk Mechanism
}

\author{
Yi tao Pan \\ Gang Feng Liu \\ Harbin Institute of Technology \\ Jizhuang Fan ( $\sim$ fanjizhuang@hit.edu.cn ) \\ Harbin Institute of Technology \\ Shu Qi Wang \\ Harbin Institute of Technology \\ Yuan Yuan Chen \\ Harbin Institute of Technology
}

Harbin Institute of Technology https://orcid.org/0000-0001-5792-9089

\section{Original Article}

Keywords: 4-SPS/U four-level rigid trunk mechanism, Screw theory , Kinematics modeling , Workspace

Posted Date: September 20th, 2021

DOI: https://doi.org/10.21203/rs.3.rs-895704/v1

License: (c) (i) This work is licensed under a Creative Commons Attribution 4.0 International License.

Read Full License 


\section{Design and kinematic analysis of a 4-SPS/U-based four-level rigid trunk mechanism}

Yi-Tao Pan, born in 1991, is currently a doctoral student at State Key Laboratory of Robotics and System (HIT), Harbin Institute of Technology.

E-mail: 349461505@qq.com

Gang-Feng Liu, born in 1980, is currently an associate professor at Harbin Institute of Technology, a PhD tutor at State Key Laboratory of Robotics and System (HIT). He received his PhD degree from Harbin Institute of Technology, China. His research interests include configuration design and intelligent control of special operation Robot.

E-mail: liugangfeng@hit.edu.cn

Ji-Zhuang Fan, born in 1976, is currently an professor at Harbin Institute of Technology, a PhD tutor at State Key Laboratory of Robotics and System (HIT). He received his PhD degree from Harbin Institute of Technology, China. His research interests include bionic robots and service robots in extreme environments.

E-mail: fanjizhuang@hit.edu.cn

Shu-Qi Wang, born in 1994, is currently a doctoral student at State Key Laboratory of Robotics and System (HIT), Harbin Institute of Technology.

E-mail: 489385182@qq.com

Yuan Chen, born in 1976, is currently an professor at Shandong University . He received his PhD degree from Harbin Institute of Technology, China. His research interests include robot mechanism and motion control, mechanical engineering test technology.

E-mail: pytstudent@163.com

\section{Corresponding author: Ji-Zhuang Fan E-mail: fanjizhuang@hit.edu.cn}




\title{
Design and kinematic analysis of a 4-SPS/U-based four-level rigid trunk mechanism
}

\author{
Yi-Tao Pan ${ }^{1}$ • Gang-Feng Liu ${ }^{1} \cdot$ Ji-Zhuang Fan ${ }^{1} \cdot$ Shu-Qi Wang ${ }^{1} \cdot$ Yuan $_{\text {Chen }}{ }^{2}$
}

Received June xx, 201x; revised February xx, 201x; accepted March xx, 201x

(C) Chinese Mechanical Engineering Society and Springer-Verlag Berlin Heidelberg 2017

\begin{abstract}
A 4-SPS/U four-level rigid trunk mechanism, with SPS as the driving branch and $U$ as the middle constrained driven branch, is innovatively proposed in this paper. It can improve the flexibility of hexapod mobile robots in posture adjustment in various motion modes such as walking, water propulsion, climbing, and rolling. Firstly, the screw theory is adopted to calculate the degree of freedom of the 4-SPS/U four-level rigid trunk mechanism. Secondly, a combination of closed vector method and decoupling method of eigenstructure assignment has been applied to constructing the inverse kinematics solution, and deriving the velocity and acceleration models as well as analyzing the high posture flexibility in workspace of the trunk mechanism. Thirdly, theoretical simulation data diagram of the movement branch chain displacement, end height, speed and acceleration of the trunk mechanism are calculated through theoretical numerical examples, and the excellent motion characteristics of the 4-SPS/U type fourlevel rigid trunk mechanism are analyzed. Finally, a quantitative comparison was made between the theoretical simulation data and the experimental data of the experimental prototype. The error rates of the variation curves of the displacement length, height, velocity and acceleration of the driving branch chain were $0.8 \%$, $0.2 \%, 0.5 \%$ and $0.9 \%$, which verified the correctness and reliability of the theoretical derivation.
\end{abstract}

Keywords: 4-SPS/U four-level rigid trunk mechanism $•$ Screw theory $\bullet$ Kinematics modeling $\bullet$ Workspace

\section{Introduction}

More and more researchers are using multi-motor mobile robots for search and rescue tasks such as sign detection and identification of trapped survivors in special

Ji-Zhuang Fan

fanjizhuang@hit.edu.cn

1 State Key Laboratory of Robotics and System (HIT), Harbin Institute of Technology, Haerbin 150000, China

2 School of Mechanical, Electrical \& Information Engineering, ShanDong University, Weihai, Hangzhou 264200, China complex scenarios, such as searching for surviving injured people [1-2] in natural disasters such as battlefields, earthquakes, and mines. Since the battlefield, earthquake or mine disaster environments have conventional obstacles, such as slopes, steps, trenches, pits and pillars, etc., there are also more complex terrain environments such as large-scale rocks, large span trenches, ultra-low bridges, extremely narrow caves, and uncertain depths of water. The multi-motor mobile robots such as wheeled, tracked, and legged robots, which are considered only from the aspect of conventional leg mechanism innovation, can hardly overcome such complex environments. Therefore, it is necessary to improve the structural innovation design of other parts of the robot to further improve the multi-motion flexibility, motion space, and stiffness of the multi-motion mobile robot. This will enable the multimotion mobile robot to quickly reach the survivor's location instead of diving into the dangerous and complex environment, and to detect and provide feedback on the terrain, environment and casualty situation.

At present, Li Zhihai [3] designed a wheel-foot hybrid wall mobile robot. The University of Science and Technology of China [4] developed a wheel-leg composite mobile robot HyTRo-I. The Shenyang Institute of Automation, Chinese Academy of Sciences [5] developed a wheel-track composite mobile robot, and Phipps et al [6] proposed a deformable hexapod mobile robot (Hex-A-). Ball), etc. Most of these combined mobile robots are considered only in terms of the combination of wheel, track and leg type, while the role of the robot trunk mechanism is 
neglected. Without the trunk mechanism and the leg mechanism, it is difficult to ensure the ability of multimotion posture adjustment in rugged and narrow space, large slope and large-scale rock, earthquake or mine disaster search and rescue. Therefore, the trunk mechanism is of great importance for the coordinated whole-body motion of multimotion mode mobile robots [7].

The WABIAN-2R robot developed by Waseda University, Japan, has a tandem drive trunk consisting of two parts - the hip and the waist. The pelvis rotates so that the robot's legs can be fully extended when striding forward, unlike other robots that need to bend their knees to maintain balance. In addition, it can also achieve complex movements such as skimming the legs outward and stepping in place on a soft cushion to maintain balance. However, its waist mechanism also has problems [8-9] such as complex structure and heavy mass. The i Struct ape space exploration robot jointly developed by the German Artificial Intelligence Research Center and the University of Bremen [10] has a 6-degree-of-freedom parallel mechanism in its trunk, and this parallel mechanism makes the robot have a good load-bearing capacity, improves the rigidity of the robot, reduces the error accumulation, and improves the motion accuracy. Although the low mass and low inertia of the moving parts improve the dynamic performance of the system, this mechanism has the problem of small range of motion, which limits the large and flexible movements of the robot. The i Cub robot developed by the European Association of Innovative Universities [11] uses a differential mechanism based on a wire rope drive for the two degrees of freedom of pitch and deflection, and a servo motor drive for the degrees of freedom of lateral tilt. This kind of flexible rope drive makes the waist of the humanoid robot flexible, but this driving method also has the problem of small driving force/moment, and it is difficult to maintain sufficient stiffness when driving large loads. The springbased rope-driven 4-SPS/U trunk joint mechanism proposed by Yitao Pan [12]is not only able to achieve two degrees of freedom of rotation by the rope drive, but also to adjust the stiffness change on the branch chain by each spring. However, the greater the spring stiffness, the greater the required rope tension, and the greater the driving force assigned to the motor. And because the spring stiffness is related to many factors such as length and geometry, it is difficult to grasp the stable stiffness of the trunk mechanism in this way.

The complex environment and diverse operational requirements put higher demands on the environmental adaptability and whole-body coordination of the multimotor hexapod mobile robot. Therefore, the trunk mechanism should not only have a large working space to improve the flexibility of the hexapod mobile robot to achieve the posture adjustment [13] of walking, water propulsion, climbing and rolling, but also have a large stiffness [14] to maintain the posture accuracy and large load capacity at the end of multiple motion modes [15].A Khali [16-18] et al. investigated a non-conventional parallel mechanism 3-SPS (ball-prism-ball) based on electromagnetically actuated spherical intra-articular brakes, and used the inverse of the Jacobi matrix to determine the shortcut space analysis, and verified that the 3-SPS (ballprism-ball) parallel mechanism can improve the degrees of freedom, working space, and flexibility more than platforms such as PRS without sacrificing stiffness and positioning accuracy.

Therefore, this paper adopts the SPS type as the driving support chain and designs a 4-SPS/U type four-level rigid trunk mechanism as the trunk mechanism of the hexapod mobile robot. Firstly, the screw theory is used to calculate the degrees of freedom of the 4-SPS/U-based four-level rigid trunk mechanism; secondly, the mathematical models of velocity and acceleration in the mechanism are constructed, and the workspace of the 4-SPS/U-based fourlevel rigid mechanism is calculated by the numerical search method [19-20]; finally, a quantitative comparison between the simulation data of the numerical algorithm and the experimental data is given to verify the correctness of the kinematic model of the mechanism. Based on the above theoretical demonstration, it is shown that the mechanism can not only overcome the shortcomings of single rigid parallel mechanism with low range of motion, but also ensure the multi-motor hexapod mobile robot to achieve the coordinated change of multi-motor posture diversity in the unknown complex environment through this trunk mechanism. It provides a reference basis for improving the adaptability and reliability of multi-motor hexapod robots in search and rescue missions.

\section{Based on 4-SPS/U type four-level rigid trunk mechanism}

\subsection{Innovative design of the trunk mechanism}

In order to make the trunk mechanism flexible in structure and convenient in control, and also to be able to analyze and calculate its superior motion performance by using the principle of mechanism, as shown in Fig.1, a 4SPS/U-based four-level rigid trunk mechanism is innovatively designed in this paper. The structure is composed of four levels, each of which adopts the same 4SPS/U type rigid parallel mechanism design, i.e., it consists 
of a mobile platform, a relative static platform, and a restraining and driving chain connecting the mobile platform and the relative static platform. As shown in the middle diagram of Fig. 1, the drive chain consists of four SPS-type rigid drive chains with the same structure. As shown in the upper left diagram of Fig. 1, the drive motor is firstly installed with a specific set of connecting screw drive at the end of the drive motor shaft, and the front end of the drive screw is passed through the inner ring of the bearing until the rear edge of the screw is blocked by the outside of the inner ring of the bearing. The motor with the screw is then mounted at the lower end of the upper mobile sleeve in each drive chain. As shown in the upper and lower right diagrams in Fig.1, each drive chain is assembled with the (upper and lower) ball heads at the (upper and lower) ball seats of the movable and static levels respectively, and fixed to the levels by the upper and lower gland, then the upper end of the upper mobile sleeve is passed through the ball head and fixed to the upper ball head by screws, and then the front part of the drive screw at the lower end of the upper mobile sleeve is assembled into the lower mobile sleeve. The lower end of the upper mobile sleeve is inserted into the upper end of the lower mobile sleeve, and the lower end of the lower mobile sleeve is inserted through the lower ball and fixed to the lower ball by means of a nut. As shown in the lower left diagram of Fig. 1, bearings are first installed at both ends of the upper and lower restraining chains, and then the upper and lower restraining chains are connected on both sides by the shaft end of the cross shaft to form the middle passive restraining chain $\mathrm{U}$.

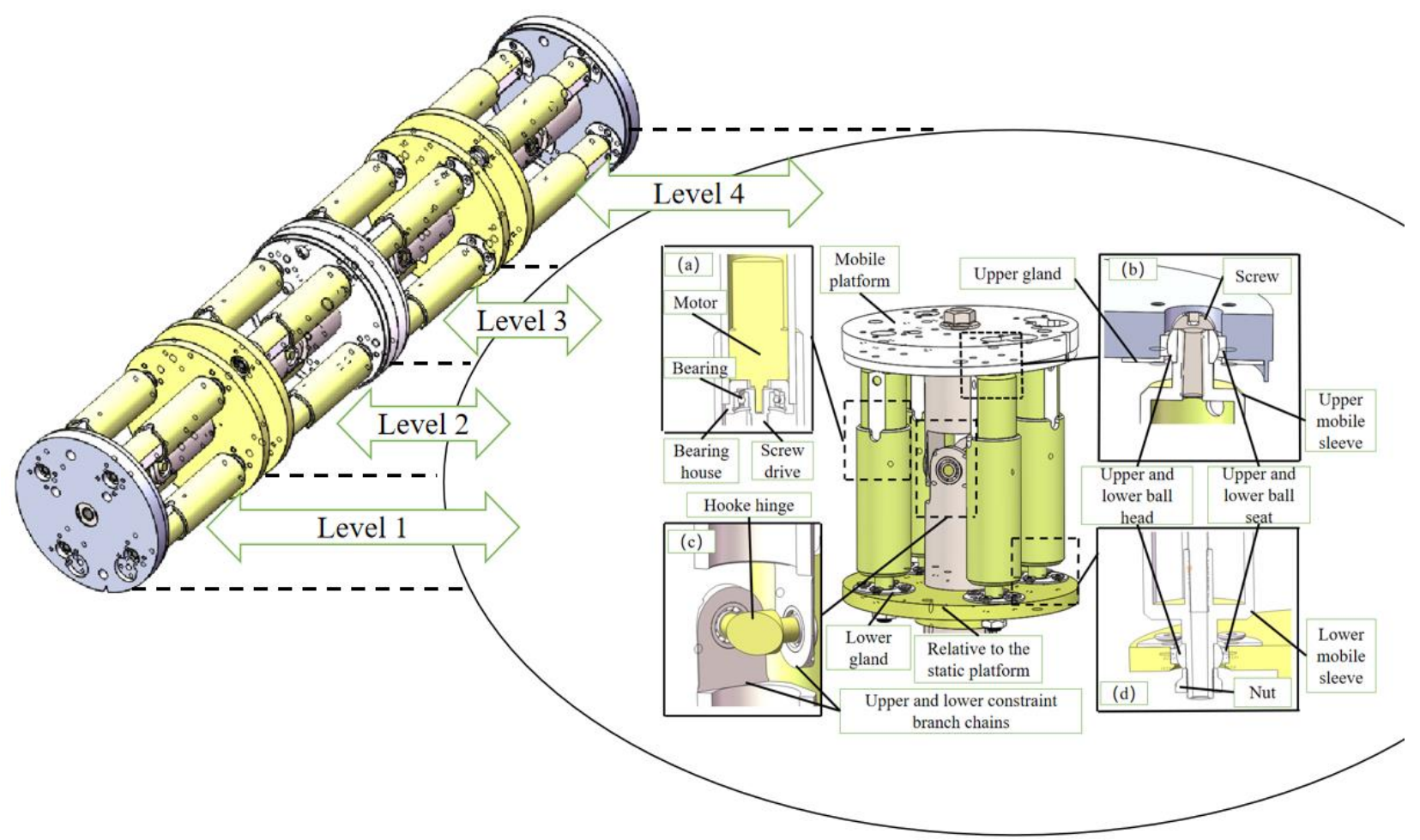

Fig. 1. Three-dimensional structure of the trunk mechanism.

As shown in Fig. 2, the ball sub connected to the static platform is set as the first motion sub, the relative moving sub of the driving support chain is set as the second motion sub, and the ball sub connected to the mobile platform is set as the third motion sub. The coordinate systems $\mathrm{O}_{\mathrm{A}}-\mathrm{X}_{\mathrm{A}} \mathrm{Y}_{\mathrm{A}} \mathrm{Z}_{\mathrm{A}}, \quad \mathrm{O}_{\mathrm{B}}-\mathrm{X}_{\mathrm{B}} \mathrm{Y}_{\mathrm{B}} \mathrm{Z}_{\mathrm{B}}, \mathrm{O}_{\mathrm{C}}-\mathrm{X}_{\mathrm{C}} \mathrm{Y}_{\mathrm{C}} \mathrm{Z}_{\mathrm{C}}, \mathrm{O}_{\mathrm{D}^{-}}$ $X_{D} Y_{D} Z_{D}$ and $O_{E}-X_{E} Y_{E} Z_{E}$ are located on the static platform and the mobile platform $(1,2,3,4)$ respectively, and the $\mathrm{O}_{\mathrm{A}}$ point is located at the center of the circle of the static platform with radius $r$. The $X_{A}$ axis is along $A_{3} A_{1}$, the $Y_{A}$ axis is along $\mathrm{A}_{4} \mathrm{~A}_{2}$, and the $\mathrm{Z}_{\mathrm{A}}$ axis is in accordance with the right-hand rule. Points $\mathrm{O}_{\mathrm{B}}, \mathrm{O}_{\mathrm{C}}, \mathrm{O}_{\mathrm{D}}, \mathrm{O}_{\mathrm{E}}$ are located at the center of the circle of the mobile platform $(1,2,3,4)$ with radius $r$. The $\mathrm{X}_{\mathrm{B}}, \mathrm{X}_{\mathrm{E}}, \mathrm{X}_{\mathrm{J}}, \mathrm{X}_{\mathrm{N}}$ axes are along $\mathrm{B}_{1,3} \mathrm{~B}_{1,1}, \mathrm{~B}_{2,3} \mathrm{~B}_{2,1}$, $\mathrm{B}_{3,3} \mathrm{~B}_{3,1}, \mathrm{~B}_{4,3} \mathrm{~B}_{4,1}, \mathrm{Y}_{\mathrm{B}}, \mathrm{Y}_{\mathrm{E}}, \mathrm{Y}_{\mathrm{J}}, \mathrm{Y}_{\mathrm{N}}$ axes are along $\mathrm{B}_{1,4} \mathrm{~B}_{1,2}$, $\mathrm{B}_{2,4} \mathrm{~B}_{2,2}, \mathrm{~B}_{3,4} \mathrm{~B}_{3,2}, \mathrm{~B}_{4,4} \mathrm{~B}_{4,2}$, and $\mathrm{Z}_{\mathrm{B}}, \mathrm{Z}_{\mathrm{E}}, \mathrm{Z}_{\mathrm{J}}$, and $\mathrm{Z}_{\mathrm{N}}$ axes conform to the right-hand rule. 


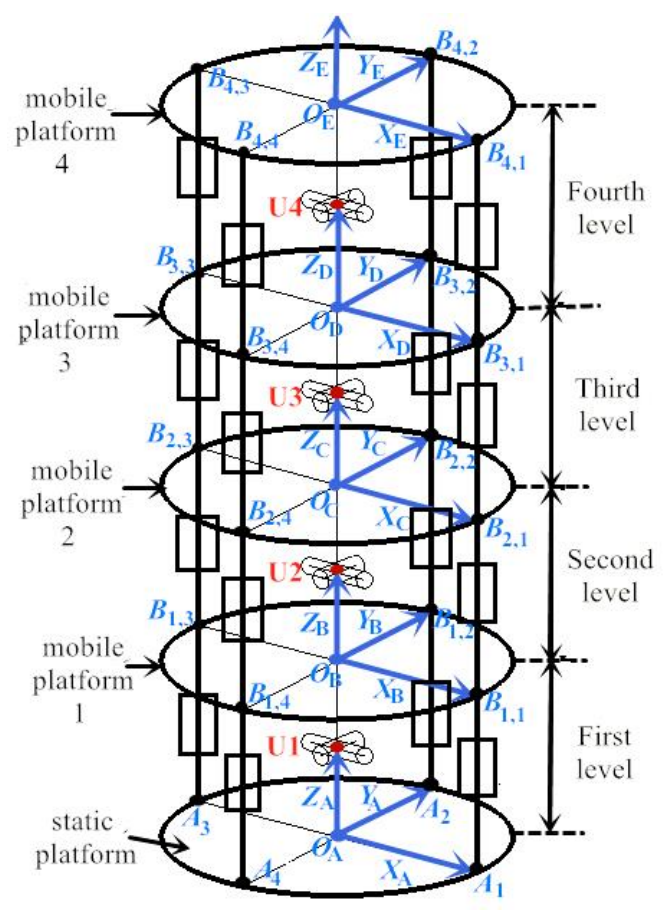

Fig. 2. Structural schematic diagram of the trunk mechanism.

As shown in Fig. 3(G), the head, forelegs, hind legs and propeller propulsion mechanism are first installed at the end of the first and fourth levels of the trunk mechanism, then the mid legs are installed between the second and third levels, and finally the roller mechanism is installed between the first and second levels and between the third and fourth levels, respectively, which constitutes a multi-motor hexapod mobile robot based on the 4-SPS/U type four-level rigid trunk mechanism. As shown in Fig. 3 (a), when the trunk mechanism is in linear attitude, the robot can achieve linear crawling motion with triangular gait. As shown in Fig. 3 (b), when the robot faces a narrow space between obstacles, the trunk mechanism is deformed into an "S" shaped posture, which enables it to traverse and walk quickly and flexibly. As shown in Fig. 3 (c), when the trunk mechanism is deformed into a "C" pose, the robot can crawl around the obstacle with a fixed diameter R2. As shown in Fig. 3 (d), when the robot is climbing over obstacles, such as stairs and trenches, the trunk mechanism can be bent at different levels to achieve the adjustment of the center of gravity between the front, middle and hind legs during climbing, thus improving the ability of climbing and stability. If the robot is on a smooth and gentle slope, it can first contract its six legs and then achieve differential rolling motion of the robot through the rollers (1 and 2) in the trunk mechanism, as shown in Fig. 3 (e). In the underwater environment, the trunk mechanism can produce a variety of changes in the robot's posture, thus enabling the propeller propulsion mechanism to produce vector propulsion in different directions, as shown in Fig. 3 (f).

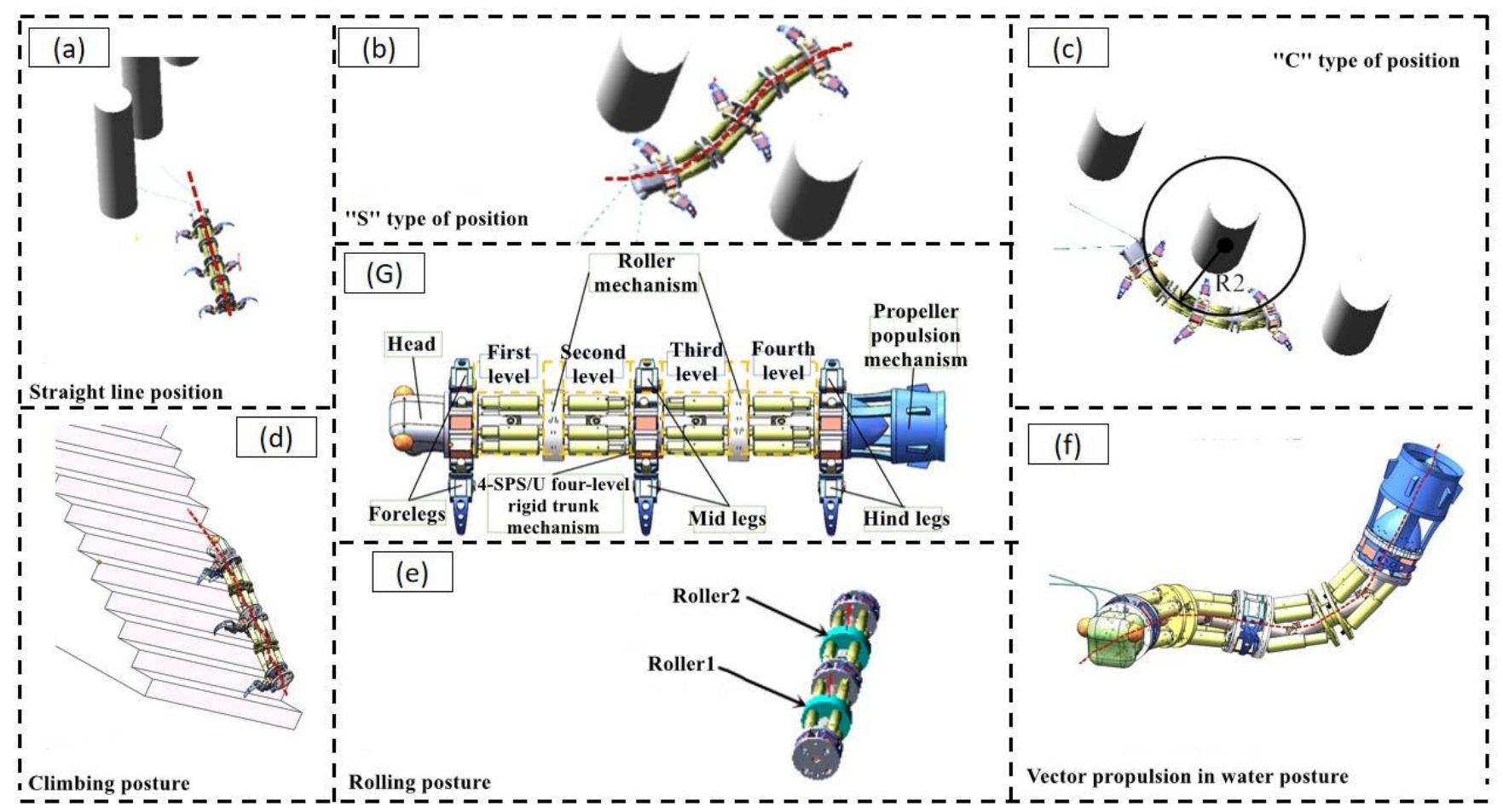

Fig. 3. Posture change of hexapod robot based on 4-SPS/U four-level rigid trunk mechanism. 


\subsection{Calculation of degrees of freedom based on a 4- SPS/U-type four-level rigid trunk mechanism}

The modified Kutzbach-Gru"bler formula [21] is used to calculate the degrees of freedom of this mechanism:

$$
M=d\left(n^{*}-g-1\right)+\sum_{i=1}^{g} f_{i}+v-\zeta
$$

$\mathrm{M}$ denotes the number of degrees of freedom of the mechanism; $d$ is the order of the mechanism, which depends on the common constraint $\lambda$, where $d=6-\lambda ; n *$ denotes the number of members including the frame; $g$ denotes the number of kinematic subassemblies; $f_{i}$ denotes the degree of freedom of the first kinematic subassembly; $v$ denotes the redundancy constraint of the multi-loop parallel mechanism, which is equal to the number of independent redundancy constraints after removing the common constraint, where $v$ $=t-k ; t$ denotes the maximum irrelevant group of the antihelix system of all the branches of the multi-loop parallel mechanism after removing the common constraint denotes the number of antihelices of all branches after removing the common constraints; $k$ denotes the maximum irrelevant group of antihelices of all branches of the multi-loop parallel mechanism after removing the common constraints; $\zeta$ denotes the local degrees of freedom present in the mechanism.

It is assumed that the driving branch chain based on the 4-SPS/U type four-level trunk mechanism moves in this branch chain coordinate system with the following screw system:

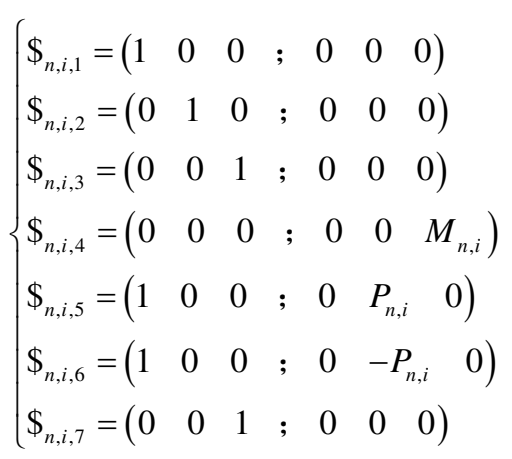

Where the subscript $\mathrm{n}$ denotes the $\mathrm{nth}$ level $(n=1,2,3,4)$; the subscript $i$ denotes the $i$-th branch drive chain of the mechanism $(i=1,2,3,4) ; M_{n, i}$ denotes the second kinematic sub-axis direction of the $i$-th drive branch in the $n$-th level trunk mechanism; $P_{n, i}$ denotes the position of the third kinematic sub-axis of the $i$-th drive branch in the $n$-th level trunk mechanism relative to the coordinate system of the branch.

The linear Eq. (2) shows that there are six linearly independent screws in the first, second, third and fourth levels of the trunk mechanism. The reciprocal product of the six linearly independent screws in each level is calculated by the formula $\$_{n, i, q^{\circ}} \$_{n}^{r}=0$ ( $\left.\mathrm{q}=1-7\right)$, which shows that the linear Eq.(2) has no solution, indicating that there is no antihelix in the $n$th level of the trunk mechanism. It is inverse, i.e. $\lambda_{n}=\operatorname{Rank}\left(\$^{c}\right)$.Therefore, the driving branch chains $A_{i} B_{j, i} 、 B_{j, i} B_{j+1, i}(j$ take 1,2,3) are all zero terminal constraint kinematic chains, i.e., there is no common constraint for this trunk mechanism, so $d_{n}=6-0=6$.

In the reference coordinate systems $\mathrm{O}_{\mathrm{B}}-\mathrm{X}_{\mathrm{B}} \mathrm{Y}_{\mathrm{B}} Z_{\mathrm{B}}$, $\mathrm{O}_{C}-\mathrm{X}_{C} Y_{C} Z_{C}, O_{D}-X_{D} Y_{D} Z_{D}, O_{E}-X_{E} Y_{E} Z_{E}$, the kinematic screw systems $\$ \mathrm{n}$ of the intermediate constrained branch chains $\mathrm{O}_{\mathrm{A}} \mathrm{O}_{\mathrm{B}}, \mathrm{O}_{\mathrm{B}} \mathrm{O}_{\mathrm{C}}, \mathrm{O}_{\mathrm{C}} \mathrm{O}_{\mathrm{D}}, \mathrm{O}_{\mathrm{D}} \mathrm{O}_{\mathrm{E}}$ are:

$$
\left\{\begin{array}{l}
\$_{n, 1}=\left(\begin{array}{lllllll}
1 & 0 & 0 & ; & 0 & 0 & 0
\end{array}\right) \\
\$_{n, 2}=\left(\begin{array}{lllllll}
0 & 1 & 0 & ; & 0 & 0 & 0
\end{array}\right)
\end{array}\right.
$$

From Eq.(3), it can be seen that the two moving helices in the nth level of the trunk mechanism are linearly independent, i.e., the reciprocal product of the antihelix $\$_{n}^{r}$ $\left(L_{n}^{r}, M_{n}^{r}, N_{n}^{r} ; P_{n}^{r}, Q_{n}^{r}, R_{n}^{r}\right)$ of the screw system is 0 . The reciprocal product formula can calculate the antihelix of each level of the trunk mechanism as follows:

$$
\left\{\begin{array}{l}
\hat{\phi}_{n, 1}^{r}=\left(\begin{array}{lllllll}
1 & 0 & 0 & ; & 0 & 0 & 0
\end{array}\right) \\
\hat{\phi}_{n, 2}^{r}=\left(\begin{array}{lllllll}
0 & 1 & 0 & ; & 0 & 0 & 0
\end{array}\right) \\
\hat{\phi}_{n, 3}^{r}=\left(\begin{array}{lllllll}
0 & 0 & 1 & ; & 0 & 0 & 0
\end{array}\right) \\
\hat{\phi}_{n, 4}^{r}=\left(\begin{array}{lllllll}
0 & 0 & 0 & ; & 0 & 0 & 1
\end{array}\right)
\end{array}\right.
$$

From Eq. (4), it can be seen that the screw system of the mechanism restricts the movement of the $\mathrm{x}$ axis, $\mathrm{y}$ axis, $\mathrm{z}$ axis and rotation of the $\mathrm{z}$ axis in the nth level of the trunk mechanism, then the nth level mechanism has $t_{n}=4, k_{n}=4$. Then according to the equation $v_{n}=t_{n}-k_{n}$ can be obtained: $v_{\mathrm{n}}=4-4=0$. By observing the arrangement of the four kinematic branches in the nth level of the 4-SPS/U- based four-level rigid trunk mechanism, it can be seen that there are local degrees of freedom, i.e. $\zeta_{\mathrm{n}}=4$. Therefore, the degrees of freedom of the 4-SPS/U-based four-level rigid trunk mechanism can be calculated from Eq. (1) as:

$$
\begin{aligned}
& \boldsymbol{M}_{\mathrm{n}}=\boldsymbol{d}_{\mathrm{n}}\left(\boldsymbol{n}_{\boldsymbol{n}}^{*}-\boldsymbol{g}_{\mathrm{n}}-1\right)+\sum_{\boldsymbol{i}_{\mathrm{n}}=1}^{\boldsymbol{g}} \boldsymbol{f}_{\boldsymbol{i}_{\mathrm{n}}}+v_{\mathrm{n}}-\zeta_{\mathrm{n}} \\
& =6 \times(11-14-1)+(3 \times 4 \times 2+4+2)-4=2
\end{aligned}
$$

From the above equation, it follows that the trunk mechanism can achieve the nth 2-degree of freedom rotation. 3 Kinematic modeling of 4-SPS/U four-level rigid trunk mechanism 


\subsection{Inverse position solution modeling}

As shown in Fig. 4, the coordinate systems $\mathrm{O}_{\mathrm{U} 1}-$ $\mathrm{X}_{\mathrm{U} 1} \mathrm{Y}_{\mathrm{U} 1} \mathrm{Z}_{\mathrm{U} 1}, \quad \mathrm{O}_{\mathrm{U} 2}-\mathrm{X}_{\mathrm{U} 2} \mathrm{Y}_{\mathrm{U} 2} \mathrm{Z}_{\mathrm{U} 2}, \quad \mathrm{O}_{\mathrm{U} 3}-\mathrm{X}_{\mathrm{U} 3} \mathrm{Y}_{\mathrm{U} 3} \mathrm{Z}_{\mathrm{U} 3}, \quad \mathrm{O}_{\mathrm{U} 4}{ }^{-}$ $\mathrm{X}_{\mathrm{U} 4} \mathrm{Y}_{\mathrm{U} 4} \mathrm{Z}_{\mathrm{U} 4}$ are respectively established at the center of the hooke hinge $U(1,2,3,4)$. The ball head points at the two ends of the four SPS branches of each level in the trunk mechanism are respectively and symmetrically distributed on the static platform $\left(\mathrm{A}_{1}, \mathrm{~A}_{2}, \mathrm{~A}_{3}, \mathrm{~A}_{4}\right)$ and on the mobile platform $1\left(\mathrm{~B}_{1,1}, \mathrm{~B}_{1,2}, \mathrm{~B}_{1,3}, \mathrm{~B}_{1,4}\right)$, on the mobile platform 2 $\left(\mathrm{B}_{2,1}, \mathrm{~B}_{2,2}, \mathrm{~B}_{2,3}, \mathrm{~B}_{2,4}\right)$, on the mobile platform $3\left(\mathrm{~B}_{3,1}, \mathrm{~B}_{3,2}\right.$, $\left.\mathrm{B}_{3,3}, \mathrm{~B}_{3,4}\right)$, on the mobile platform $4\left(\mathrm{~B}_{4,1}, \mathrm{~B}_{4,2}, \mathrm{~B}_{4,3}, \mathrm{~B}_{4,4}\right)$. The distance from the center of circle to ball head point of both the static platform and the mobile platform is $r$. In the middle constraint branch chain of the first, second, third and fourth levels of the trunk mechanism, the hooke hinge is respectively located between the static platform and the mobile platform, and between two mobile platforms. And the distance from the hooke hinge center $U(1,2,3,4)$ to the center point between every two platforms is $l_{n}$.

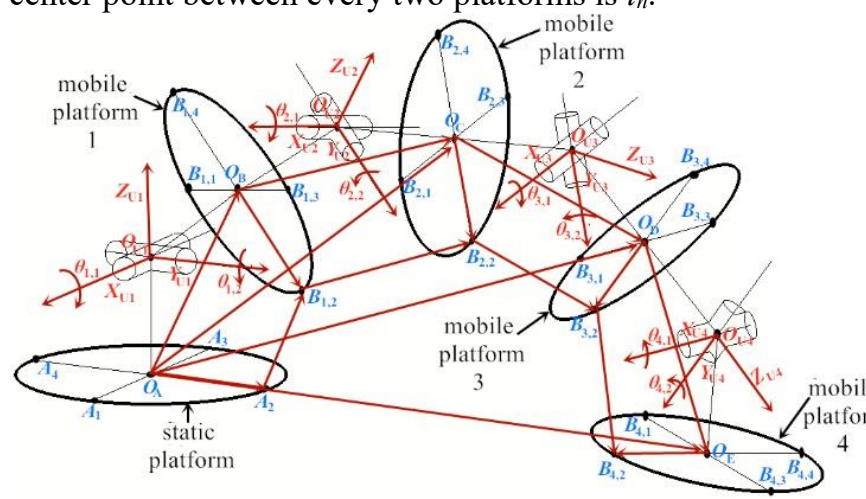

Fig. 4. Motion principle of a four-level rigid trunk mechanism based on 4-SPS/U

As shown in Fig.4, the coordinate system $\mathrm{O}_{\mathrm{U} 1^{-}}$ $\mathrm{X}_{\mathrm{U} 1} \mathrm{Y}_{\mathrm{U} 1} \mathrm{Z}_{\mathrm{U} 1}$ at the center of Hooke's hinge $\mathrm{U}_{1}$ in the first level of the 4-SPS/U-based four-level rigid trunk mechanism is rotated around the $\mathrm{Y}_{\mathrm{U} 1}$ axis by $\theta_{1,2}$, and the dynamic coordinate system $O_{B}-X_{B} Y_{B} Z_{B}$ is rotated around the $X_{U 1}$ axis by $\theta_{1,1}$, then the flush of the dynamic coordinate system $O_{B}-X_{B} Y_{B} Z_{B}$ with respect to the static coordinate system $\mathrm{O}_{\mathrm{A}}-\mathrm{X}_{\mathrm{A}} \mathrm{Y}_{\mathrm{A}} \mathrm{Z}_{\mathrm{A}}$ can be found The transformation matrix is given by:

$$
\begin{aligned}
& { }_{A}^{B} T=\operatorname{Trans}\left(0,0, l_{n}\right) \operatorname{Rot}\left(y, \theta_{1,2}\right) \operatorname{Rot}\left(x, \theta_{1,1}\right) \operatorname{Trans}\left(0,0, l_{n}\right)
\end{aligned}
$$

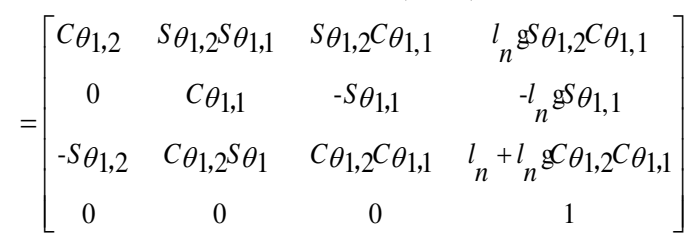

Where $c \theta$ indicates $\cos \theta, \mathrm{s} \theta$ denotes $\sin \theta$.
As depicted in Fig 4, according to the vector closed quadrangle [22-23] $\mathrm{O}_{\mathrm{A}} \mathrm{A}_{2} \mathrm{~B}_{1,2} \mathrm{O}_{\mathrm{B}}$ formed by the red dotted line arrows, the change equation of each branch chain's length change $A_{i} B_{1, i}$ at the first level $(n=1)$ can be obtained as:

$$
A_{i} B_{1, i}=O_{A} O_{B}+O_{B} B_{1, i}-O_{A} A_{i}
$$

where One end of the intermediate restraint support chain $\mathrm{U} 1$ is connected to the static platform, and the other end is connected to the dynamic platform, so the vector $\mathrm{O}_{\mathrm{A}} \mathrm{O}_{\mathrm{B}}=\left[l \cdot \mathrm{S} \theta_{1,2} \mathrm{C} \theta_{1,1}, \quad-l \cdot \mathrm{S} \theta_{1,1}, \quad l+l \cdot \mathrm{C} \theta_{1,2} \mathrm{C} \theta 1,1\right]^{\mathrm{T}}$. The coordinates of point $\mathrm{B}_{1, \mathrm{i}}$ in the dynamic coordinate system $\mathrm{O}_{\mathrm{B}}-\mathrm{X}_{\mathrm{B}} \mathrm{Y}_{\mathrm{B}} Z_{\mathrm{B}}$ can be expressed as: $\mathrm{B}_{1, \mathrm{i}}=\mathrm{r}\left(\cos \lambda_{1, \mathrm{i}}, \sin \lambda_{1, \mathrm{i}}, 0\right)^{\mathrm{T}}$, and the coordinates of point $A_{i}$ in the static coordinte system $\mathrm{O}_{\mathrm{A}}-\mathrm{X}_{\mathrm{A}} \mathrm{Y}_{\mathrm{A}} \mathrm{Z}_{\mathrm{A}}$ can be expressed as: $\mathrm{O}_{\mathrm{A}} \mathrm{A}_{\mathrm{i}}=\mathrm{A}_{\mathrm{i}}=\mathrm{r}\left(\cos \lambda_{1, \mathrm{i}}, \sin \lambda_{1, \mathrm{i}}\right.$, $0)^{\mathrm{T}}$, and $\mathrm{O}_{\mathrm{B}} \mathrm{B}_{1, \mathrm{i}}={ }_{B}^{A} R \cdot B_{1, i}, \lambda_{1, \mathrm{i}}=(2 \pi / 3) \times(\mathrm{i}-1)$. The $\mathrm{B}_{1, \mathrm{i}}$ coordinates are of the following form:

$$
\left\{\begin{array} { l } 
{ \boldsymbol { B } _ { 1 , 1 } = [ \begin{array} { l l l } 
{ \boldsymbol { r } } & { 0 } & { 0 }
\end{array} ] ^ { T } } \\
{ \boldsymbol { B } _ { 1 , 2 } = [ \begin{array} { l l l } 
{ 0 } & { \boldsymbol { r } } & { 0 }
\end{array} ] ^ { T } } \\
{ \boldsymbol { B } _ { 1 , 3 } = [ \begin{array} { l l l } 
{ - \boldsymbol { r } } & { 0 } & { 0 }
\end{array} ] ^ { T } } \\
{ \boldsymbol { B } _ { 1 , 4 } = [ \begin{array} { l l l } 
{ 0 } & { - \boldsymbol { r } } & { 0 }
\end{array} ] ^ { T } }
\end{array} \left\{\begin{array}{l}
A_{1,1}=\left[\begin{array}{lll}
\boldsymbol{r} & 0 & 0
\end{array}\right]^{T} \\
A_{1,2}=\left[\begin{array}{lll}
0 & \boldsymbol{r} & 0
\end{array}\right]^{T} \\
A_{1,3}=\left[\begin{array}{lll}
-\boldsymbol{r} & 0 & 0
\end{array}\right]^{T} \\
A_{1,4}=\left[\begin{array}{lll}
0 & -\boldsymbol{r} & 0
\end{array}\right]^{T}
\end{array}\right.\right.
$$

Substituting the above Eq. (7) into Eq. (6), the inverse solution equation for the vector length of the kinematic branch chain in the first level can be obtained as:

$$
\boldsymbol{l}_{1, \boldsymbol{i}}=\left\|\boldsymbol{A}_{1, \boldsymbol{i}} \boldsymbol{B}_{1, \boldsymbol{i}}\right\|
$$

Similarly, as shown in Fig. 4, the coordinate system $\mathrm{O}_{\mathrm{U} 2}-\mathrm{X}_{\mathrm{U} 2} \mathrm{Y}_{\mathrm{U} 2} \mathrm{Z}_{\mathrm{U} 2}$ at the center of Hooke's hinge $\mathrm{U}_{2}$ in the second level of the 4-SPS/U-based four-level rigid trunk mechanism rotates around the $\mathrm{Y}_{\mathrm{U} 2}$ axis by $\theta_{2,2}$, and the dynamic coordinate system $\mathrm{O}_{\mathrm{C}}-\mathrm{X}_{\mathrm{C}} \mathrm{Y}_{\mathrm{C}} \mathrm{Z}_{\mathrm{C}}$ rotates around the $\mathrm{X}_{\mathrm{U} 2}$ axis by $\theta_{2,1}$, then the homogeneous transformation matrix of the moving coordinate system $\mathrm{O}_{\mathrm{C}}-\mathrm{X}_{\mathrm{C}} \mathrm{Y}_{\mathrm{C}} \mathrm{Z}_{\mathrm{C}}$, relative to the static coordinate system $\mathrm{O}_{\mathrm{A}}-\mathrm{X}_{\mathrm{A}} \mathrm{Y}_{\mathrm{A}} \mathrm{Z}_{\mathrm{A}}$, can be obtained as:

$$
{ }_{A}^{C} T={ }_{A}^{B} T \cdot \operatorname{Trans}\left(0,0, l_{n}\right) \operatorname{Rot}\left(y, \theta_{2,2}\right) \operatorname{Rot}\left(x, \theta_{2,1}\right) \operatorname{Trans}\left(0,0, l_{n}\right)
$$

As shown in Fig. 4, the vector closed quadrilateral [2223] $\mathrm{O}_{\mathrm{B}} \mathrm{B}_{1,2} \mathrm{~B}_{2,2} \mathrm{O}_{\mathrm{C}}$ diagram formed by the red dashed arrows can be obtained for each branch chain length $\mathrm{B}_{1, \mathrm{i}} \mathrm{B}_{2, \mathrm{i}}$ in the second level $(\mathrm{n}=2)$ :

$$
\boldsymbol{B}_{1, i} \boldsymbol{B}_{2, \boldsymbol{i}}=\boldsymbol{O}_{\boldsymbol{B}} \boldsymbol{O}_{\boldsymbol{C}}+\boldsymbol{O}_{\boldsymbol{C}} \boldsymbol{B}_{2, \boldsymbol{i}}-\boldsymbol{O}_{\boldsymbol{B}} \boldsymbol{B}_{1, \boldsymbol{i}}
$$

Where $\mathrm{O}_{\mathrm{B}} \mathrm{O}_{\mathrm{C}}=\mathrm{O}_{\mathrm{A}} \mathrm{O}_{\mathrm{C}}-\mathrm{O}_{\mathrm{A}} \mathrm{O}_{B}$, from Eq. (9) we can obtain the position vector $\mathrm{O}_{\mathrm{A}} \mathrm{O}_{\mathrm{C}}$. The coordinates of the point $\mathrm{B}_{2, \mathrm{i}}$ in the static coordinate system $\mathrm{O}_{\mathrm{A}}-\mathrm{X}_{\mathrm{A}} \mathrm{Y}_{\mathrm{A}} \mathrm{Z}_{\mathrm{A}}$ can be expressed as: $\mathrm{O}_{C} \mathrm{~B}_{2, i}={ }_{A}^{C} R \cdot B_{2, i}$. The coordinates of point $\mathrm{B}_{2, \mathrm{i}}$ in the dynamic coordinate system $\mathrm{O}_{\mathrm{C}}-\mathrm{X}_{\mathrm{C}} \mathrm{Y}_{\mathrm{C}} \mathrm{Z}_{\mathrm{C}}$ can be expressed as: $\mathrm{B}_{2, \mathrm{i}}=\mathrm{r}\left(\cos \lambda_{2, \mathrm{i}}, \sin \lambda_{2, \mathrm{i}}, 0\right) \mathrm{T}, \lambda_{2, \mathrm{i}}=(2 \pi / 3) \times(\mathrm{i}-1)$, and its $\mathrm{B}_{2, \mathrm{i}}$ coordinates are of the following form: 


$$
\left\{\begin{array}{l}
\boldsymbol{B}_{2,1}=\left[\begin{array}{lll}
\boldsymbol{r} & 0 & 0
\end{array}\right]^{T} \\
\boldsymbol{B}_{2,2}=\left[\begin{array}{lll}
0 & \boldsymbol{r} & 0
\end{array}\right]^{T} \\
\boldsymbol{B}_{2,3}=\left[\begin{array}{lll}
-\boldsymbol{r} & 0 & 0
\end{array}\right]^{T} \\
\boldsymbol{B}_{2,4}=\left[\begin{array}{lll}
0 & -\boldsymbol{r} & 0
\end{array}\right]^{T}
\end{array}\right.
$$

Substituting the above Eq. (11) into Eq. (10), the inverse solution equation for the vector length of the kinematic branch chain in the second level can be obtained as:

$$
\boldsymbol{l}_{2, \boldsymbol{i}}=\left\|\boldsymbol{B}_{1, i} \boldsymbol{B}_{2, \boldsymbol{i}}\right\|
$$

Similarly, as shown in Fig. 4, the coordinate system $\mathrm{O}_{\mathrm{U} 3}-\mathrm{X}_{\mathrm{U} 3} \mathrm{Y}_{\mathrm{U} 3} \mathrm{Z}_{\mathrm{U} 3}$ at the center of Hooke's hinge $\mathrm{U}_{3}$ in the third level of the 4-SPS/U-based four-level rigid trunk mechanism rotates around the $\mathrm{Y}_{\mathrm{U} 3}$ axis by $\theta_{3,2}$, and the dynamic coordinate system $\mathrm{O}_{\mathrm{D}}-\mathrm{X}_{\mathrm{D}} \mathrm{Y}_{\mathrm{D}} \mathrm{Z}_{\mathrm{D}}$ rotates around the $\mathrm{X}_{\mathrm{U} 3}$ axis by $\theta_{3,1}$, then the homogeneous transformation matrix of the moving coordinate system $\mathrm{O}_{D}-\mathrm{X}_{\mathrm{D}} \mathrm{Y}_{\mathrm{D}} \mathrm{Z}_{\mathrm{D}}$, relative to the static coordinate system $\mathrm{O}_{\mathrm{A}}-\mathrm{X}_{\mathrm{A}} \mathrm{Y}_{\mathrm{A}} \mathrm{Z}_{\mathrm{A}}$, can be derived as:

$$
{ }_{A}^{D} T={ }_{A}^{C} T \cdot \operatorname{Trans}\left(0,0, l_{n}\right) \operatorname{Rot}\left(y, \theta_{3,2}\right) \operatorname{Rot}\left(x, \theta_{3,1}\right) \operatorname{Trans}\left(0,0, l_{n}\right)
$$

As shown in Fig. 4, the vector closed quadrilateral [22-23] $\mathrm{O}_{\mathrm{D}} \mathrm{O}_{\mathrm{C}} \mathrm{B}_{2,2} \mathrm{~B}_{3,2}$ formed by the red dashed arrows can be derived from the diagram of the third level $(n=3)$ for each branch chain length $\mathrm{B}_{2, \mathrm{i}} \mathrm{B}_{3, \mathrm{i}}$ with the variation equation:

$$
\boldsymbol{B}_{2, i} \boldsymbol{B}_{3, i}=\boldsymbol{O}_{C} \boldsymbol{O}_{\boldsymbol{D}}+\boldsymbol{O}_{\boldsymbol{D}} \boldsymbol{B}_{3, i}-\boldsymbol{O}_{\boldsymbol{B}} \boldsymbol{B}_{2, i}
$$

where $\mathrm{O}_{C} \mathrm{O}_{D}=\mathrm{O}_{A} \mathrm{O}_{D}-\mathrm{O}_{A} \mathrm{O}_{C}$, the position vector $\mathrm{O}_{A} \mathrm{O}_{D}$ can be obtained from Eq. (13). The coordinates of the point $\mathrm{B}_{3, \mathrm{i}}$ in the static coordinate system $\mathrm{O}_{\mathrm{A}}-\mathrm{X}_{\mathrm{A}} \mathrm{Y}_{\mathrm{A}} \mathrm{Z}_{\mathrm{A}}$ can be expressed as: $\mathrm{O}_{\mathrm{D}} \mathrm{B}_{3, \mathrm{i}}={ }_{A}^{D} R \cdot B_{3, i}$. The coordinates of the point $\mathrm{B}_{3, \mathrm{i}}$ in the dynamic coordinate system $\mathrm{O}_{\mathrm{D}}-\mathrm{X}_{\mathrm{D}} \mathrm{Y}_{\mathrm{D}} \mathrm{Z}_{\mathrm{D}}$ can be expressed as $B_{3, i}=r\left(\cos \lambda_{3, i}, \sin \lambda_{3, i}, 0\right)^{\mathrm{T}}, \lambda_{3, i}=(2 \pi / 3) \times(i-1)$. The coordinates have the following form:

$$
\left\{\begin{array}{l}
\boldsymbol{B}_{3,1}=\left[\begin{array}{lll}
\boldsymbol{r} & 0 & 0
\end{array}\right]^{T} \\
\boldsymbol{B}_{3,2}=\left[\begin{array}{lll}
0 & \boldsymbol{r} & 0
\end{array}\right]^{T} \\
\boldsymbol{B}_{3,3}=\left[\begin{array}{lll}
-\boldsymbol{r} & 0 & 0
\end{array}\right]^{T} \\
\boldsymbol{B}_{3,4}=\left[\begin{array}{lll}
0 & -\boldsymbol{r} & 0
\end{array}\right]^{T}
\end{array}\right.
$$

Substituting the above Eq. (15) into Eq. (14), the inverse solution equation for the vector length of each branch chain in the third level can be obtained as:

$$
\boldsymbol{l}_{3, i}=\left\|\boldsymbol{B}_{2, i} \boldsymbol{B}_{3, i}\right\|
$$

Similarly, as shown in Fig. 4, the coordinate system $\mathrm{O}_{\mathrm{U} 4}$ $\mathrm{X}_{\mathrm{U} 4} \mathrm{Y}_{\mathrm{U} 4} \mathrm{Z}_{\mathrm{U} 4}$ at the center of Hooke's hinge $\mathrm{U}_{4}$ in the fourth level of the 4-SPS/U type four-level rigidity rotates around the $\mathrm{Y}_{\mathrm{U} 4}$ axis by $\theta_{4,2}$, and the dynamic coordinate system $\mathrm{O}_{\mathrm{E}^{-}}$ $\mathrm{X}_{\mathrm{E}} \mathrm{Y}_{\mathrm{E}} \mathrm{Z}_{\mathrm{E}}$ rotates around the $\mathrm{X}_{\mathrm{U} 4}$ axis by $\theta_{4,1}$ Then the homogeneous transformation matrix of the moving coordinate system $O_{\mathrm{E}}-\mathrm{X}_{\mathrm{E}} \mathrm{Y}_{\mathrm{E}} \mathrm{Z}_{\mathrm{E}}$, relative to the static coordinate system $\mathrm{O}_{\mathrm{A}}-\mathrm{X}_{\mathrm{A}} \mathrm{Y}_{\mathrm{A}} \mathrm{Z}_{\mathrm{A}}$, can be derived as :

$$
{ }_{A}^{E} T={ }_{A}^{D} T \cdot \operatorname{Trans}\left(0,0, l_{n}\right) \operatorname{Rot}\left(y, \theta_{4,2}\right) \operatorname{Rot}\left(x, \theta_{4,1}\right) \operatorname{Trans}\left(0,0, l_{n}\right)
$$

As shown in Fig. 4, the vector closed quadrilateral [2223] $\mathrm{O}_{\mathrm{E}} \mathrm{O}_{\mathrm{D}} \mathrm{B}_{3,2} \mathrm{~B}_{4,2}$ diagram formed by the red dashed arrows can be derived from the equation for the variation of each branch length $\mathrm{B}_{3, \mathrm{i}} \mathrm{B}_{4, \mathrm{i}}$ in the fourth level $(\mathrm{n}=4)$ :

$$
\boldsymbol{B}_{3, i} \boldsymbol{B}_{4, i}=\boldsymbol{O}_{\boldsymbol{D}} \boldsymbol{O}_{\boldsymbol{E}}+\boldsymbol{O}_{\boldsymbol{E}} \boldsymbol{B}_{4, i}-\boldsymbol{O}_{\boldsymbol{D}} \boldsymbol{B}_{3, i}
$$

where $\mathrm{O}_{\mathrm{D}} \mathrm{O}_{\mathrm{E}}=\mathrm{O}_{\mathrm{A}} \mathrm{O}_{\mathrm{E}}-\mathrm{O}_{\mathrm{A}} \mathrm{O}_{\mathrm{D}}$, the position vector $\mathrm{O}_{A} \mathrm{O}_{\mathrm{E}}$ is obtained from Eq. (17); The coordinates of the point $\mathrm{B}_{4, \mathrm{i}}$ in the static coordinate system $\mathrm{O}_{\mathrm{A}}-\mathrm{X}_{\mathrm{A}} \mathrm{Y}_{\mathrm{A}} \mathrm{Z}_{\mathrm{A}}$ can be expressed as: $\mathrm{O}_{\mathrm{E}} \mathrm{B}_{4, \mathrm{i}}={ }_{A}^{E} R \cdot B_{4, \mathrm{i}} \cdot \mathrm{B}_{4, \mathrm{i}}=\mathrm{r}\left(\cos \lambda_{4, \mathrm{i}}, \sin \lambda_{4, \mathrm{i}} 0\right)^{\mathrm{T}}, \lambda_{4, \mathrm{i}}=(2 \pi / 3) \times(\mathrm{i}-$ $1)$ in the dynamic coordinate system $O_{E}-X_{E} Y_{E} Z_{E}$, whose coordinates take the following form:

$$
\left\{\begin{array}{l}
\boldsymbol{B}_{4,1}=\left[\begin{array}{lll}
\boldsymbol{r} & \mathrm{O} & \mathrm{O}
\end{array}\right]^{\boldsymbol{T}} \\
\boldsymbol{B}_{4,2}=\left[\begin{array}{lll}
\mathrm{O} & \boldsymbol{r} & \mathrm{O}
\end{array}\right]^{\boldsymbol{T}} \\
\boldsymbol{B}_{4,3}=\left[\begin{array}{lll}
-\boldsymbol{r} & \mathrm{O} & \mathrm{O}
\end{array}\right]^{\boldsymbol{T}} \\
\boldsymbol{B}_{4,4}=\left[\begin{array}{lll}
\mathrm{O} & -\boldsymbol{r} & \mathrm{O}
\end{array}\right]^{\boldsymbol{T}}
\end{array}\right.
$$

Substituting the above Eq. (19) into Eq. (18), the inverse solution equation for the vector length of each branch chain in the fourth level can be obtained as:

$$
\boldsymbol{l}_{4, i}=\left\|\boldsymbol{B}_{3, i} \boldsymbol{B}_{4, i}\right\|
$$

\subsection{Velocity and acceleration modeling}

The four SPS-driven branched chains of the nth level of the trunk mechanism are considered as generalized inputs, denoted as $l_{n}=\left[l_{n, 1}, l_{n, 2}, l_{n, 3}, l_{n, 4}\right]^{\mathrm{T}}$. The generalized output of the $n$th level of the mobile platform is denoted as $\theta_{n}=\left[\theta_{n, 1}, \theta_{n, 2}\right]^{T}$, then the input velocity of the four SPS-driven branch chain moving subsets in the $n$th level is denoted as $\dot{l}_{n}=$ $\left[l_{n, 1}, l_{n, 2}, \dot{l}_{n, 3}, l_{n, 4}\right]^{T} ; \quad$ the input acceleration of the four SPS-driven branch chain moving subsets in the nth

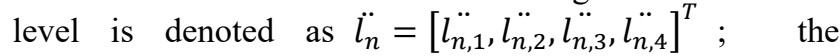
generalized output angular velocity of the nth level of the mobile platform is denoted as $\dot{\theta_{n}}=\left[\dot{\theta}_{n, 1}^{\cdot}, \theta_{n, 2}^{\cdot}\right]^{T}$; the generalized output angular acceleration of the nth level of the mobile platform is denoted as $\ddot{\theta}_{n}=\left[\theta_{n, 1}^{\ddot{1}}, \theta_{n, 2}\right]^{T}$. By taking the derivatives of Eqs. (8), (12), (16), and (20) on each side simultaneously for time $t$, the inverse solution equation [24] for the velocity of the 4-SPS/U-based fourlevel rigid trunk mechanism can be obtained as:

$$
\boldsymbol{L}_{\boldsymbol{n}} \boldsymbol{\ell}_{\boldsymbol{n}}^{\&}=\boldsymbol{J}_{\boldsymbol{n}, \boldsymbol{i}, \boldsymbol{j}} \Theta_{\boldsymbol{n}}^{\&}(\boldsymbol{i}=1,2,3,4 ; j=1,2)
$$

Where the element of $i$ th row and $j$ th column of $\mathrm{J}_{i, j}$ in the nth level are obtained from that $\mathrm{A}_{\mathrm{i}} \mathrm{B}_{1, \mathrm{i}}, \mathrm{B}_{1, \mathrm{i}} \mathrm{B}_{2, \mathrm{i}}, \mathrm{B}_{2, \mathrm{i}} \mathrm{B}_{3, \mathrm{i}}, \mathrm{B}_{3, \mathrm{i}} \mathrm{B}_{4, \mathrm{i}}$ take the derivative of in Eq. (8), (12), (16) and (20); $\mathrm{L}_{n}$ is 
the $l_{n, \mathrm{i}}$ length matrix of the $\mathrm{n}$ level drive branch chain. Assuming that $\mathrm{J}_{\mathrm{n}}^{*}$ is the positive Jacobian matrix of the mechanism, which is: $J_{n}^{*}=L_{n}^{-1} \cdot J_{n, i, j}$.

Therefore, if the velocities of the two adjacent drive branches in the nth level are known, we can solve the positive equation for the velocity of the 4-SPS/U-based four-level rigid trunk mechanism as follows:

$$
\mathcal{O}_{\mathbf{n}}^{\&}=\left(\boldsymbol{J}_{\boldsymbol{n}}^{*}\right)^{-1} \boldsymbol{\&}
$$

Where: the inverse Jacobian matrix $\left(J_{n}^{*}\right)^{-1}$ is:

$$
\left(\boldsymbol{J}_{n}^{*}\right)^{-1}=\left[\begin{array}{cc}
\frac{\left(\partial \boldsymbol{l}_{n, 1} / \partial \theta_{n, 1}\right)}{\boldsymbol{l}_{n, 1}\left\|\boldsymbol{J}_{n}^{*}\right\|} & -\frac{\left(\partial \boldsymbol{l}_{n, 2} / \partial \theta_{n, 1}\right)}{\boldsymbol{l}_{\boldsymbol{n}, 2}\left\|\boldsymbol{J}_{n}^{*}\right\|} \\
-\frac{\left(\partial \boldsymbol{l}_{n, 1} / \partial \theta_{n, 2}\right)}{\boldsymbol{l}_{\boldsymbol{n}, 1}\left\|\boldsymbol{J}_{n}^{*}\right\|} & \frac{\left(\partial \boldsymbol{l}_{n, 2} / \partial \theta_{n, 2}\right)}{\boldsymbol{l}_{\boldsymbol{n}, 2}\left\|\boldsymbol{J}_{n}^{*}\right\|}
\end{array}\right]
$$

By deriving both sides of Eq. (21) simultaneously for time $t$, the inverse equation for the acceleration based on the 4-SPS/U type four-level rigid trunk mechanism can be found as:

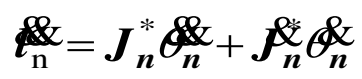

Where $j_{n}^{*}=L_{n}^{-1} J_{n, l, j}$, whose values is:

$$
\boldsymbol{J}_{n}^{*}=\left[\begin{array}{ll}
\frac{1}{\boldsymbol{l}_{n, 1}}\left(\frac{\partial^{2} \boldsymbol{l}_{n, 1}}{\partial^{2} \theta_{n, 1}}+\frac{\partial^{2} \boldsymbol{l}_{n, 1}}{\partial \theta_{n, 1} \partial \theta_{n, 2}}\right) & \frac{1}{l_{n, 1}}\left(\frac{\partial^{2} \boldsymbol{l}_{n, 1}}{\partial^{2} \theta_{n, 2}}+\frac{\partial^{2} \boldsymbol{l}_{n, 1}}{\partial \theta_{n, 2} \partial \theta_{n, 1}}\right) \\
\frac{1}{l_{n, 2}}\left(\frac{\partial^{2} \boldsymbol{l}_{n, 2}}{\partial^{2} \theta_{n, 1}}+\frac{\partial^{2} \boldsymbol{l}_{n, 2}}{\partial \theta_{n, 1} \partial \theta_{n, 2}}\right) & \frac{1}{l_{n, 2}}\left(\frac{\partial^{2} \boldsymbol{l}_{n, 2}}{\partial^{2} \theta_{n, 2}}+\frac{\partial^{2} \boldsymbol{l}_{n, 2}}{\partial \theta_{n, 2} \partial \theta_{n, 1}}\right) \\
\frac{1}{l_{n, 3}}\left(\frac{\partial^{2} \boldsymbol{l}_{n, 3}}{\partial^{2} \theta_{n, 1}}+\frac{\partial^{2} \boldsymbol{l}_{n, 3}}{\partial \theta_{n, 1} \partial \theta_{n, 2}}\right) & \frac{1}{l_{n, 3}}\left(\frac{\partial^{2} \boldsymbol{l}_{n, 3}}{\partial^{2} \theta_{n, 2}}+\frac{\partial^{2} \boldsymbol{l}_{n, 3}}{\partial \theta_{n, 2} \partial \theta_{n, 1}}\right) \\
\frac{1}{l_{n, 4}}\left(\frac{\partial^{2} \boldsymbol{l}_{n, 4}}{\partial^{2} \theta_{n, 1}}+\frac{\partial^{2} \boldsymbol{l}_{n, 4}}{\partial \theta_{n, 1} \partial \theta_{n, 2}}\right) & \frac{1}{l_{n, 4}}\left(\frac{\partial^{2} \boldsymbol{l}_{n, 4}}{\partial^{2} \theta_{n, 2}}+\frac{\partial^{2} \boldsymbol{l}_{n, 4}}{\partial \theta_{n, 2} \partial \theta_{n, 1}}\right)
\end{array}\right]
$$

\section{Workspace analysis based on 4-SPS/U type four-level rigid trunk mechanism}

As shown in Fig. 4, the generalized position coordinates of the nth level of the trunk mechanism are expressed as $\phi_{\mathrm{n}, \theta}=\left[\theta_{\mathrm{n}, 1}, \theta_{\mathrm{n}, 2}\right]^{\mathrm{T}}$, where $\theta_{\mathrm{n}, 1}, \quad \theta_{\mathrm{n}, 2}$ are the $\mathrm{X}$ and $\mathrm{Y}$ axis rotation angles of the nth level of the centering coordinate system $\mathrm{O}_{\mathrm{B}}-\mathrm{X}_{\mathrm{B}} \mathrm{Y}_{\mathrm{B}} \mathrm{Z}_{\mathrm{B}}, \mathrm{O}_{\mathrm{C}}-\mathrm{X}_{\mathrm{C}} \mathrm{Y}_{\mathrm{C}} \mathrm{Z}_{\mathrm{C}}, \mathrm{O}_{\mathrm{D}}-$ $X_{D} Y_{D} Z_{D}, O_{E}-X_{E} Y_{E} Z_{E}$ with respect to the $U(1,2,3,4)$ subcentering coordinate systemO $\mathrm{U}_{1}-\mathrm{X}_{\mathrm{U} 1} \mathrm{Y}_{\mathrm{U} 1} \mathrm{Z}_{\mathrm{U} 1}, \mathrm{O}_{\mathrm{U} 2}-$ $\mathrm{X}_{\mathrm{U} 2} \mathrm{Y}_{\mathrm{U} 2} \mathrm{Z}_{\mathrm{U} 2}, \mathrm{O}_{\mathrm{U} 3}-\mathrm{X}_{\mathrm{U} 3} \mathrm{Y}_{\mathrm{U} 3} \mathrm{Z}_{\mathrm{U} 3}, \mathrm{O}_{\mathrm{U} 4}-\mathrm{X}_{\mathrm{U} 4} \mathrm{Y}_{\mathrm{U} 4} \mathrm{Z}_{\mathrm{U} 4}$. For representation simplicity it will be considered as $\theta_{\mathrm{n}, \zeta}(\zeta=1$, 2). According to Fig.5, the unit vector of nth level driving branch chain $l_{n, i}$ is $P_{n, i}^{*}$ and the bar length and the unit vector of middle constraint branch chain are respectively $L_{n}$ and $P_{n}^{Z}$, and the posture unit normal vectors of upper platform and relative lower platform in nth level are respectively $P_{n}^{S}$ and $P_{n}^{X}$.

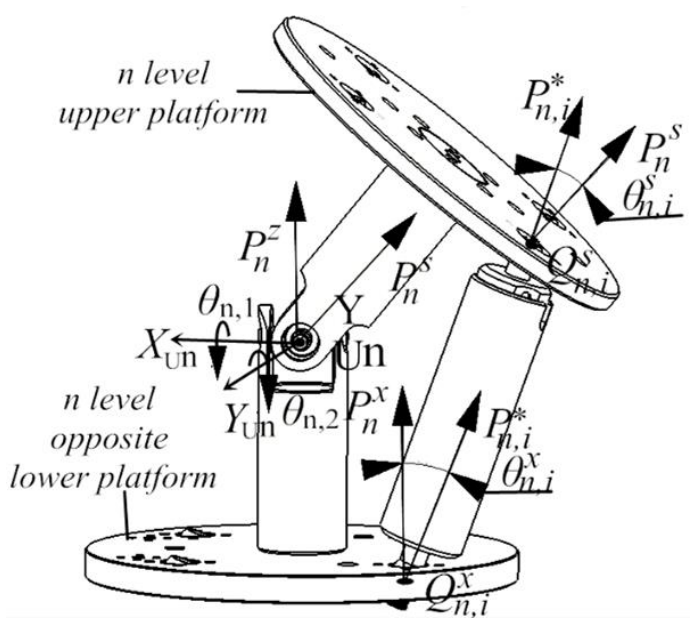

Fig. 5. The rotation angle constraint of the nth level trunk mechanism

(1) Length limitation of driving branch chain

Since there is a limit position for the relative travel distance of the rigid sleeve of the drive support chain in the nth level, there is a constraint limit for the variation of the drive support chain motion length. Assuming that the minimum and maximum lengths of each drive branch in the nth level are $l_{n, i, \min }$ and $l_{n, i, \max }$, respectively, then the constraint on the length $l_{n, i}$ of the drive branch in this trunk mechanism during the drive can be expressed as:

$$
l_{\mathrm{n}, i, \min } \leq l_{n, i} \leq l_{n, i, \max }
$$

(2) Rotation angle limitation of Joint ball head $Q_{n, i}^{S}$ that connects with the upper platform of the nth level.

As shown in Fig. 5, joint ball head is located on the upper platform of the nth level. That is, the rotation angle $\theta_{n, i}^{S}$ of the spherical joint $Q_{n, i}^{S}$ is determined by the attitude unit normal vector $P_{n}^{S}$ of the upper platform of the nth level and the unit vector $P_{n, i}^{*}$ of the driving branch chain that connects axial direction in the nth level kinestate, where the rotation angle should meet the following conditions:

$$
\left\{\begin{array}{l}
\theta_{1, i}^{s}=\arccos \frac{\boldsymbol{P}_{1, i}^{*} \cdot\left({ }_{A}^{\boldsymbol{B}} \boldsymbol{R} \cdot \boldsymbol{P}_{1}^{s}\right)}{\left|\boldsymbol{P}_{1, i}^{*} \| \boldsymbol{P}_{1}^{s}\right|} \leq \theta_{1, i}^{s, m a x} \quad(\boldsymbol{n}=1) \\
\theta_{2, i}^{s}=\arccos \frac{\boldsymbol{P}_{2, i}^{*} \cdot\left({ }_{A}^{C} \boldsymbol{R} \cdot \boldsymbol{P}_{2}^{s}\right)}{\left|\boldsymbol{P}_{2, i}^{*} \| \boldsymbol{P}_{2}^{s}\right|} \leq \theta_{2, i}^{s, \max } \quad(\boldsymbol{n}=2) \\
\theta_{3, i}^{s}=\arccos \frac{\boldsymbol{P}_{3, i}^{*} \cdot\left({ }_{A}^{\boldsymbol{D}} \boldsymbol{R} \cdot \boldsymbol{P}_{3}^{s}\right)}{\left|\boldsymbol{P}_{3, i}^{*} \| \boldsymbol{P}_{3}^{s}\right|} \leq \theta_{3, i}^{s, \max } \quad(\boldsymbol{n}=3) \\
\theta_{4, i}^{s}=\arccos \frac{\boldsymbol{P}_{4, i}^{*} \cdot\left({ }_{\boldsymbol{A}}^{\boldsymbol{E}} \boldsymbol{R} \cdot \boldsymbol{P}_{4}^{s}\right)}{\left|\boldsymbol{P}_{4, i}^{*} \| \boldsymbol{P}_{4}^{s}\right|} \leq \theta_{4, i}^{s, \max } \quad(\boldsymbol{n}=4)
\end{array}\right.
$$

Where $P_{n}^{S}$ can be obtained by the equation (8), (12), (16), (20) as: $P_{n}^{S}=[0,0,1]^{\mathrm{T}} ; \theta_{n, i}^{S, \max }$ represents the maximum rotation angle of the joint ball head connected to the upper platform in the nth level. 
(3) Rotation angle limitation of Joint ball head $Q_{n, i}^{X}$ that connects with relative lower platform of the nth level

As shown in Fig.5, joint ball head is located on relative lower platform of the nth level. That is, the rotation angle $\theta_{n, i}^{X}$ of the spherical joint $Q_{n, i}^{X}$ is determined by the posture unit normal vector $P_{n}^{X}$ of opposite lower platform of the nth level and the unit vector $P_{n, i}^{*}$ of the driving branch chain that connects with axial direction in the nth level kinstate, where the rotation angle should meet the following conditions:

$$
\left\{\begin{array}{l}
\theta_{1, i}^{\boldsymbol{x}}=\arccos \frac{\boldsymbol{P}_{1, i}^{*} \cdot\left({ }_{A}^{\boldsymbol{B}} \boldsymbol{R} \cdot \boldsymbol{P}_{1}^{\boldsymbol{x}}\right)}{\left|\boldsymbol{P}_{1, i}^{*}\right|\left|\boldsymbol{P}_{1}^{\boldsymbol{x}}\right|} \leq \theta_{1, i}^{\boldsymbol{x} \max } \quad(\boldsymbol{n}=1) \\
\theta_{2, i}^{\boldsymbol{x}}=\arccos \frac{\boldsymbol{P}_{2, i}^{*} \cdot\left({ }_{A}^{\boldsymbol{C}} \boldsymbol{R} \cdot \boldsymbol{P}_{2}^{\boldsymbol{x}}\right)}{\left|\boldsymbol{P}_{2, i}^{*} \| \boldsymbol{P}_{2}^{s}\right|} \leq \theta_{2, i}^{\boldsymbol{x}, \max } \quad(\boldsymbol{n}=2) \\
\theta_{3, i}^{\boldsymbol{x}}=\arccos \frac{\boldsymbol{P}_{3, i}^{*} \cdot\left({ }_{A}^{D} \boldsymbol{R} \cdot \boldsymbol{P}_{3}^{\boldsymbol{x}}\right)}{\left|\boldsymbol{P}_{3, i}^{*} \| \boldsymbol{P}_{3}^{\boldsymbol{x}}\right|} \leq \theta_{3, i}^{\boldsymbol{x}, \max } \quad(\boldsymbol{n}=3) \\
\theta_{4, i}^{\boldsymbol{x}}=\arccos \frac{\boldsymbol{P}_{4, i}^{*} \cdot\left({ }_{A}^{E} \boldsymbol{R} \cdot \boldsymbol{P}_{4}^{\boldsymbol{x}}\right)}{\left|\boldsymbol{P}_{4, i}^{*} \| \boldsymbol{P}_{4}^{s}\right|} \leq \theta_{4, i}^{\boldsymbol{x} \max } \quad(\boldsymbol{n}=4)
\end{array}\right.
$$

Where $P_{n}^{X}$ can be obtained by the equation (8), (12), (16), (20) as: $P_{n}^{X}=[0,0,1]^{\mathrm{T}} ; \theta_{n, i}^{X, \max }$ represents the maximum rotation angle of the joint ball head connected to upper platform of the nth level.

(4) The rotation angle limitation of hooke hinge U between the upper platform and the relative lower platform in the nth level

As shown in Fig.5, the Hooke hinge which connects between the upper platform and the relative lower platform in the nth level. That is, the rotation angle of the $U$ pair is $\theta_{\mathrm{n}, \zeta}$. When $\zeta=1, \theta_{\mathrm{n}, 1}$ is determined by the constraint branch unit normal vector $P_{n}^{Z}$ of the relative lower platform in the nth level and the posture unit normal vector $P_{n}^{S}$ of the upper platform at the nth level kinestate, which is the angle that rotates along the $\mathrm{X}$-axis. When $\zeta=2, \theta_{\mathrm{n}, 2}$ is determined by the constraint branch unit normal vector $P_{n}^{Z}$ of the opposite lower platform in the nth level and the posture unit

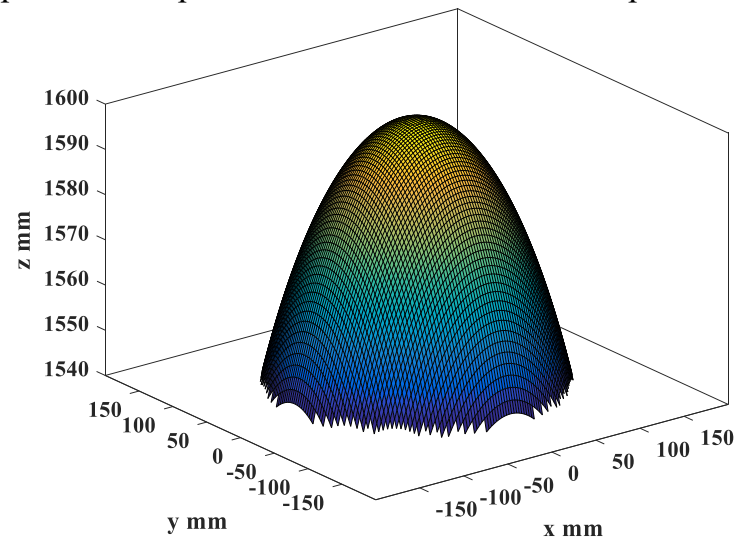

normal vector $P_{n}^{S}$ of the upper platform in the nth level kinestate, which is the angle that rotates along the Y-axis. Where the rotation angle should meet the following conditions:

$$
\left\{\begin{array}{l}
\theta_{1, \zeta}=\arccos \frac{\boldsymbol{P}_{1}^{z} \cdot\left({ }_{A}^{\boldsymbol{B}} \boldsymbol{R} \cdot \boldsymbol{P}_{1}^{s}\right)}{\left|\boldsymbol{P}_{1}^{z} \| \boldsymbol{P}_{1}^{\boldsymbol{x}}\right|} \leq \theta_{1, \zeta}^{\max } \quad(\boldsymbol{n}=1) \\
\theta_{2, \zeta}=\arccos \frac{\boldsymbol{P}_{2}^{z} \cdot\left({ }_{A}^{C} \boldsymbol{R} \cdot \boldsymbol{P}_{2}^{s}\right)}{\left|\boldsymbol{P}_{2}^{z}\right|\left|\boldsymbol{P}_{2}^{\boldsymbol{s}}\right|} \leq \theta_{2, \zeta}^{\max } \quad(\boldsymbol{n}=2) \\
\theta_{3, \zeta}=\arccos \frac{\boldsymbol{P}_{3}^{z} \cdot\left({ }_{A}^{\boldsymbol{D}} \boldsymbol{R} \cdot \boldsymbol{P}_{3}^{s}\right)}{\left|\boldsymbol{P}_{3}^{z} \| \boldsymbol{P}_{3}^{\boldsymbol{s}}\right|} \leq \theta_{3, \zeta}^{\max } \quad(\boldsymbol{n}=3) \\
\theta_{4, \zeta}=\arccos \frac{\boldsymbol{P}_{4}^{z} \cdot\left({ }_{A}^{\boldsymbol{E}} \boldsymbol{R} \cdot \boldsymbol{P}_{4}^{s}\right)}{\left|\boldsymbol{P}_{4}^{z} \| \boldsymbol{P}_{4}^{s}\right|} \leq \theta_{4, \zeta}^{\max } \quad(\boldsymbol{n}=4)
\end{array}\right.
$$

Where $P_{n}^{Z}$ can be obtained by the equation (8), (12), (16), (20) as: $P_{n}^{Z}=[0,0, \mathrm{z}]^{\mathrm{T}} ; \theta_{n, \zeta}^{\max }$ represents the maximum rotation angle of hooke hinge $U$ between the upper platform and the opposite lower platform in the nth level.

\section{Numerical examples}

\subsection{Simulation calculation of workspace}

The parameter settings of 4-SPS / U four-level rigid trunk mechanism are as follows: $\mathrm{r}=178.5 \mathrm{~mm}, \mathrm{ln}=200 \mathrm{~mm}$, $l_{n, i, \min }=222.3 \mathrm{~mm}, l_{n, i, \max }=515 \mathrm{~mm}, \theta_{n, i}^{s, \max }=90^{\circ}, \theta_{n, i}^{x, \max }=90^{\circ}$, $-45^{\circ} \leqslant \theta_{\mathrm{n}, 5} \leqslant-45^{\circ}$. With the restricted conditions in the nth level of the trunk mechanism, such as the length of driving branch chain, $U$ secondary rotation angle of middle constraint branch chain and rotation angle of joint ball head, the numerical search method [25] is employed in MATALB to perform the posture workspace simulation, thus to obtain the 3D workspace of the trunk mechanism showing in Fig.6 and Fig.7.

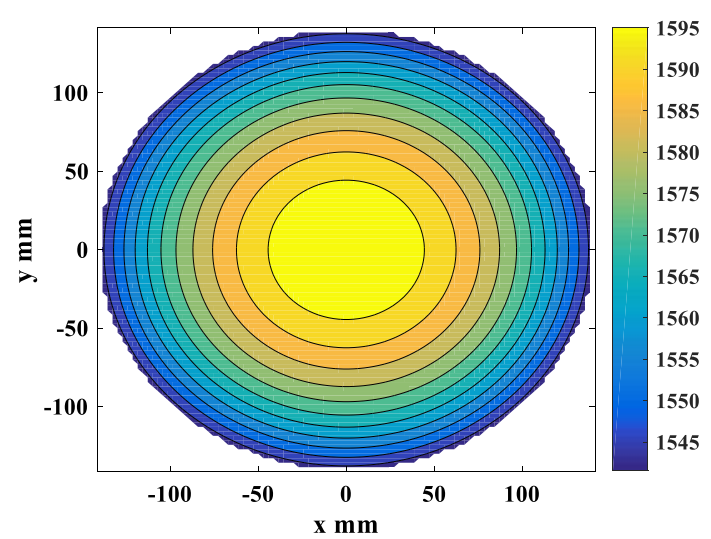


3D

(a)When the drive joint angle $\theta_{\mathrm{n}, \zeta}$ of first, second and third level are defined as $0^{\circ}$, the fourth joint angle is defined as $-45^{\circ} \leq \theta_{\mathrm{n}, \zeta} \leq 45^{\circ}$

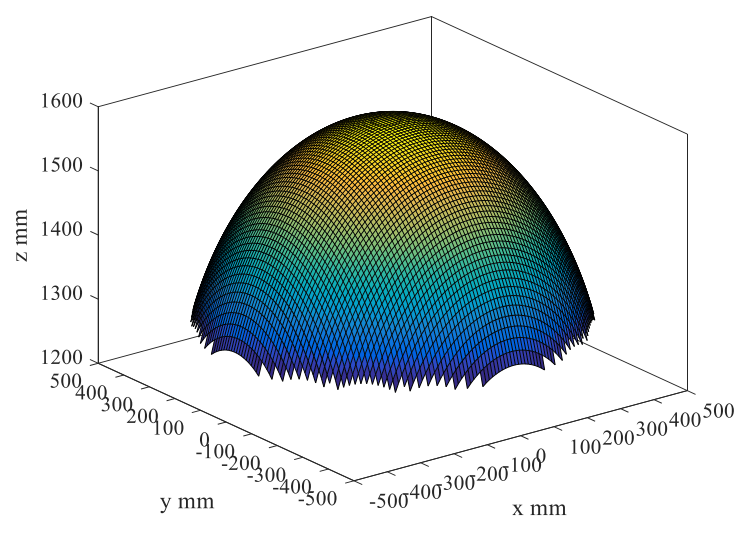

$3 \mathrm{D}$

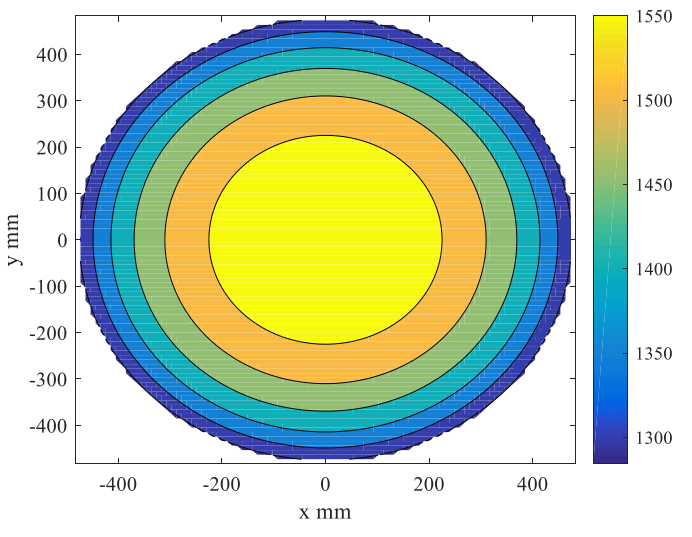

Top view

(b) When the drive joint angle $\theta_{\mathrm{n}, \zeta}$ of first and second level are defined as $0^{\circ}$, the third and fourth joint angle are defined as $-45^{\circ} \leq \theta_{\mathrm{n}, \zeta} \leq$ $45^{\circ}$

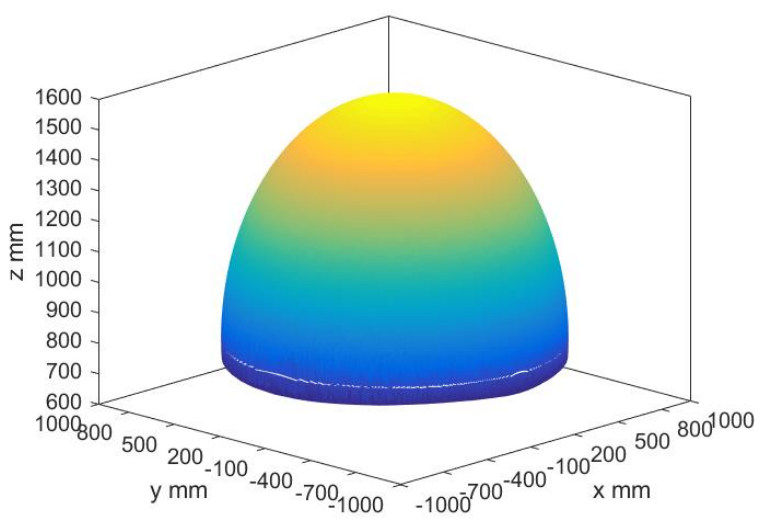

3D

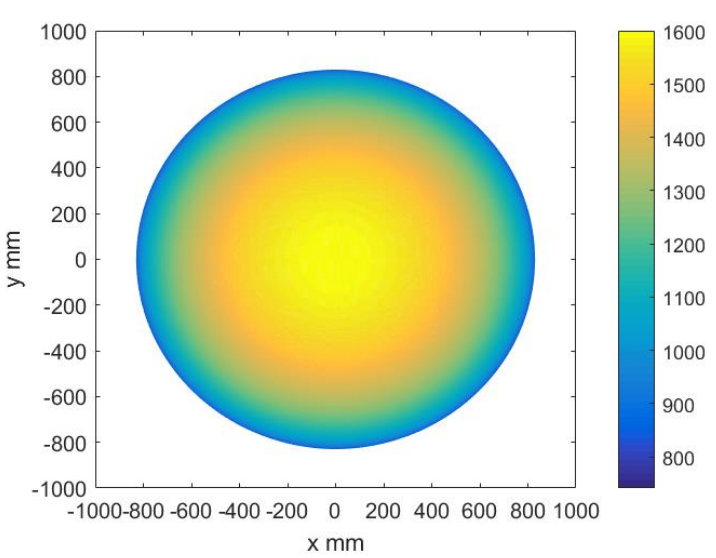

Top view

(c) When the drive joint angle $\theta_{\mathrm{n}, \zeta}$ of first level is defined as $0^{\circ}$, the second, third and fourth joint angle are defined as $-45^{\circ} \leq \theta_{\mathrm{n}, \zeta} \leq 45^{\circ}$

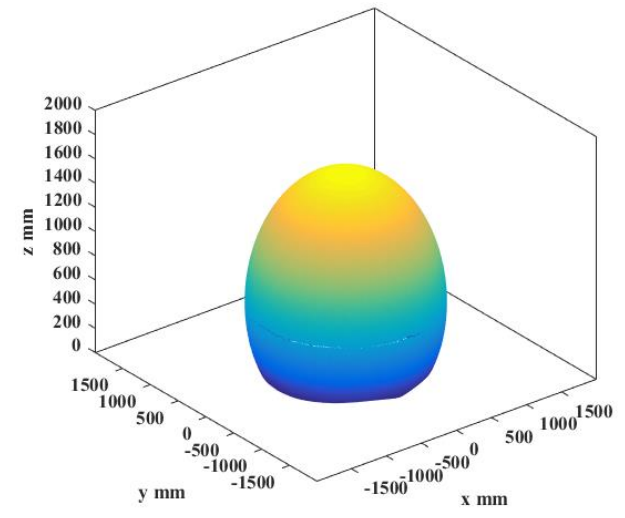

3D

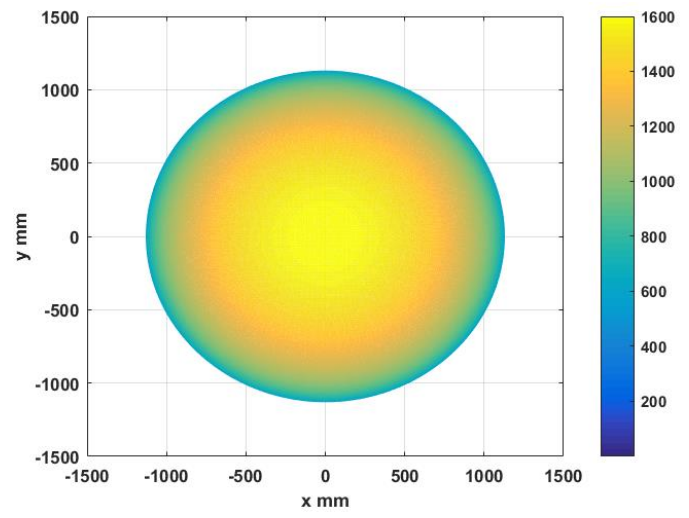

Top view

(d) When the first, second, third and fourth drive joint angles take $-45^{\circ} \leqslant \theta_{n, \zeta} \leqslant 45^{\circ}$

Fig.6 3D workspace of the 4-SPS/U four-level rigid trunk mechanism

From Fig. 6(a-d), it can be seen that the workspace of the 4-SPS/U-based four- level rigid trunk mechanism is locally spherical, and its size increases with the superposition of the number of levels in the trunk mechanism and the values of the driving joint angle $\left(\theta_{n, \zeta}\right)$ of the nth level. That is, the radius is $150 \mathrm{~mm}, 300 \mathrm{~mm}, 800 \mathrm{~mm}$, $1100 \mathrm{~mm}$, and the height is $55 \mathrm{~mm}, 300 \mathrm{~mm}, 850 \mathrm{~mm}$, $1600 \mathrm{~mm}$ respectively. 


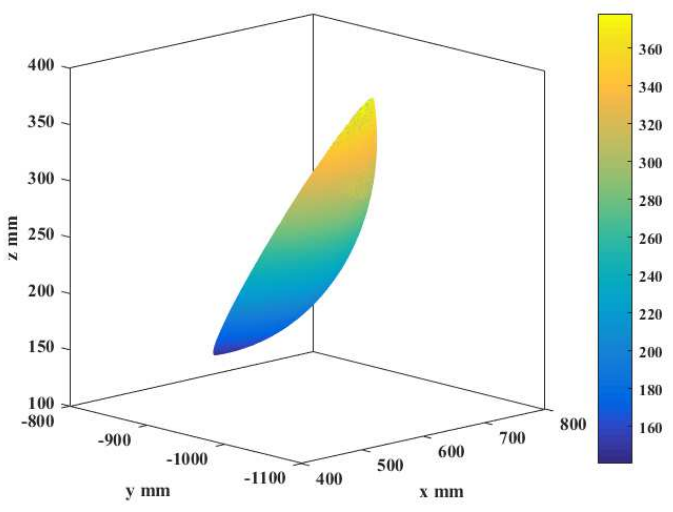

End space simulation diagram

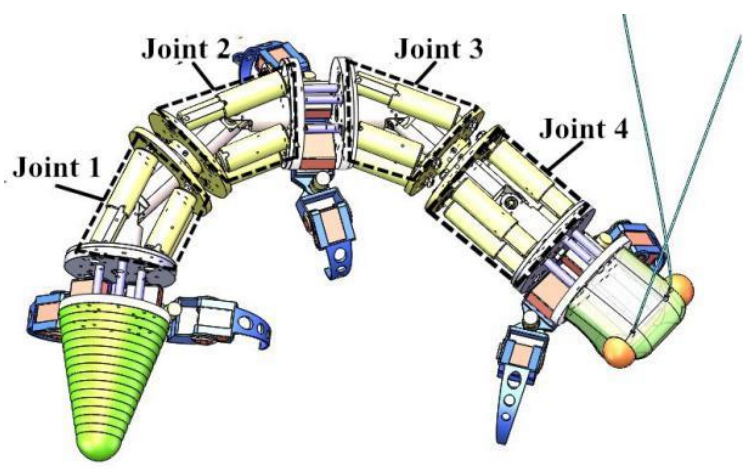

Space object diagram

(e) The end posture of the " $\mathrm{C}$ " gait is formed when the first, second and third drive joint angles take $\theta_{\mathrm{n}, \zeta}$ as $30^{\circ}$, the fourth joint angle takes $-45^{\circ} \leqslant \theta_{\mathrm{n}, \zeta} \leqslant 45^{\circ}$.

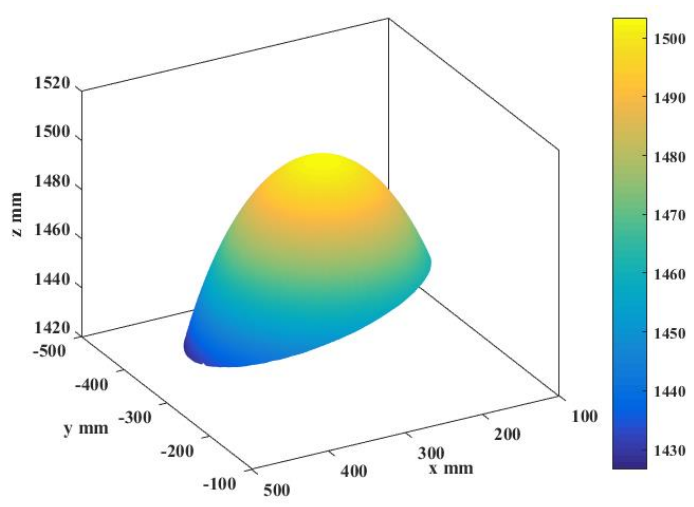

End space simulation diagram

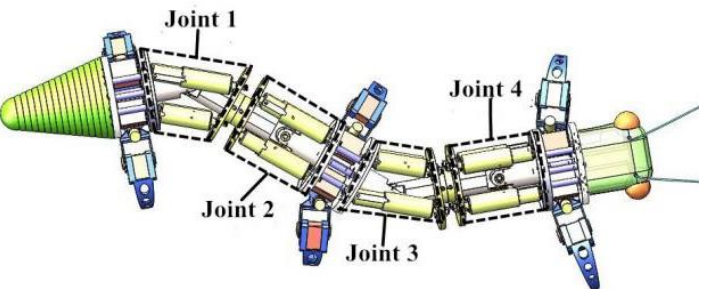

Space object diagram

(f) The end posture of the "S" gait is formed when the first and third drive joint angles take $\theta_{n, \zeta}$ as $20^{\circ}$,the second joint angle takes $\theta_{n, \zeta}$ as $0^{\circ}$ and the fourth joint angle takes $-45^{\circ} \leqslant \theta_{\mathrm{n}, \zeta} \leqslant 45^{\circ}$

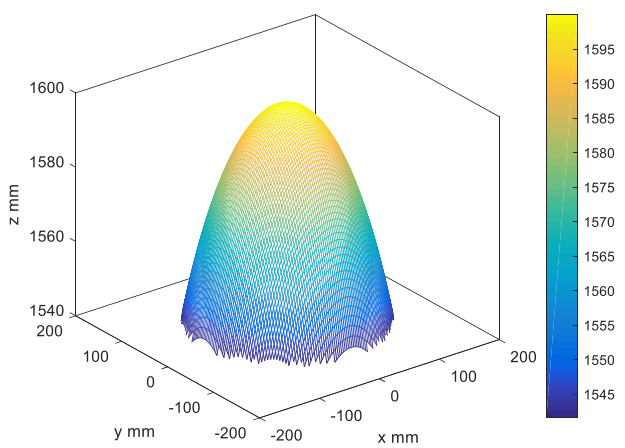

End space simulation diagram

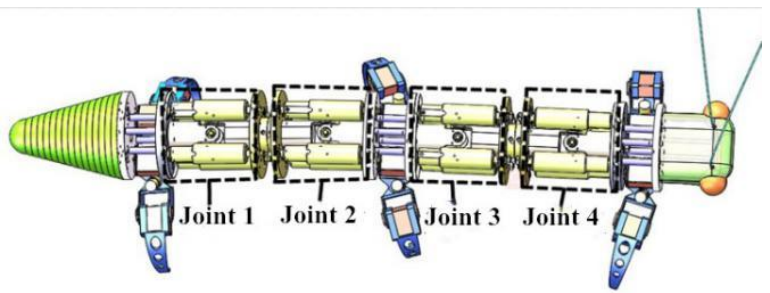

Space object diagram

(g) The end posture of the "-" gait is formed when the first second and third drive joint angles take $\theta_{n, \zeta}$ as $0^{\circ}$, the fourth joint angle takes $-45^{\circ} \leqslant \theta_{n, \zeta} \leqslant 45^{\circ}$.

Fig.7 Diverse changes on end gait workspace through the trunk mechanism adjustment of multi-motion mode hexapod mobile robot

As depicted in Fig.7 (e-g), the multi-motion mode hexapod mobile robot, controlling the diverse posture adjustment in nth level of the trunk mechanism, outfits the end gaits of fore, mid and hind legs with variable, big and flexible range of motion in workspace. As shown in Fig.7 (e), when the first, second and third drive joint angles $\theta_{\mathrm{n}, \zeta}$ are adjusted to $30^{\circ}$, and the fourth drive joint angle is $-45^{\circ}$ $\leqslant \theta_{\mathrm{n}, \zeta} \leqslant-45^{\circ}$, the trunk mechanism forms a "C" shaped bending posture, so that the robot achieves "C" shaped gait pattern motion. As illustrated in Fig.7 (f), when the first and 
third drive joints $\theta_{n, \zeta}$ are adjusted to $20^{\circ}$ and the second drive joint $\theta_{\mathrm{n}, \zeta}$ is adjusted to $0^{\circ}$, and the fourth drive joint angle is $-45^{\circ} \leqslant \theta_{\mathrm{n}, \zeta} \leqslant-45^{\circ}$, the trunk mechanism forms an "S" shaped bending posture, which enables the robot to achieve "S" shaped gait pattern motion. As shown in Fig. 7(g), when the first, second and third drive joints $\theta_{\mathrm{n}, \zeta}$ are adjusted to $0^{\circ}$, and the fourth driving joint angle is $-45^{\circ} \leqslant \theta_{\mathrm{n}, \zeta} \leqslant-45^{\circ}$, the trunk mechanism forms a straight shape, which enables the robot to achieve a straight gait style.

It can be learned from the end space simulation diagram in Fig.6-7 that we can control the drive joint angle $\theta_{n, \zeta}$ in the nth level to achieve the end position change in diverse gait patterns of the hexapod mobile robot.

\subsection{Simulation and analysis of the Kinematics Model}

Define the angle input trajectory as

$$
\left\{\begin{array}{l}
\theta_{n, 1}(t)=45 \times(\pi / 180) \times \sin ((\pi / 2) \times t) \\
\theta_{n, 2}(t)=45 \times(\pi / 180) \times \cos ((\pi / 2) \times t)
\end{array}\right.
$$

In accordance with the above parameter settings that relates to workspace simulation, MATLAB is employed to operate the simulation calculation on Eq. (8), (12), (16), (20), thus to derive curves that both length $l$ and the end of driving branch chain change their height $h$ over time in the z-axis direction. Meanwhile, in order to verify the correctness of numerical calculation, the model in SolidWorks is imported into Adams and is analyzed in simulation environment. On account of that the four driving branch chains in nth level are symmetrically distributed, as a result, there are merely two adjacent chains' simulation data being adopted and drawn in one data graph. As shown in Fig. 8, there is the length curve of two adjacent driving branch chains in nth level of the trunk mechanism. As shown in Fig.9 and Fig.10, there is the curve about ends of two adjacent driving branch chains changing their heights $\mathrm{h}$ over time in $\mathrm{z}$-axis direction. ( Here L1, h1, v1, a1 represent length, height of end, velocity and acceleration variation in MATLAB of the driving branch chain 1 in the first level of trunk mechanism. L2, h2, v2, a2 represent length, height of end, velocity and acceleration variation in MATLAB of the driving branch chain 2 in the first level of trunk mechanism. L5, h5, v5, a5 represent length, height of end, velocity and acceleration variation in MATLAB of the driving branch chain 1 in the second level of trunk mechanism. L6, h6, v6, a6 represent length, height of end, velocity and acceleration variation in MATLAB of the driving branch chain 2 in the second level of trunk mechanism. L9, h9, v9, a9 represent length, height of end, velocity and acceleration variation in MATLAB of the driving branch chain 1 in the third level of trunk mechanism. L10, h10, v10, a10 represent length, height of end, velocity and acceleration variation in MATLAB of the driving branch chain 2 in the third level of trunk mechanism. L13, h13, v13, a13 represent length, height of end, velocity and acceleration variation in MATLAB of the driving branch chain 1 in the fourth level of trunk mechanism. L14, h14, v14, a14 represent length, height of end, velocity and acceleration variation in MATLAB of the driving branch chain 2 in the fourth level of trunk mechanism.)

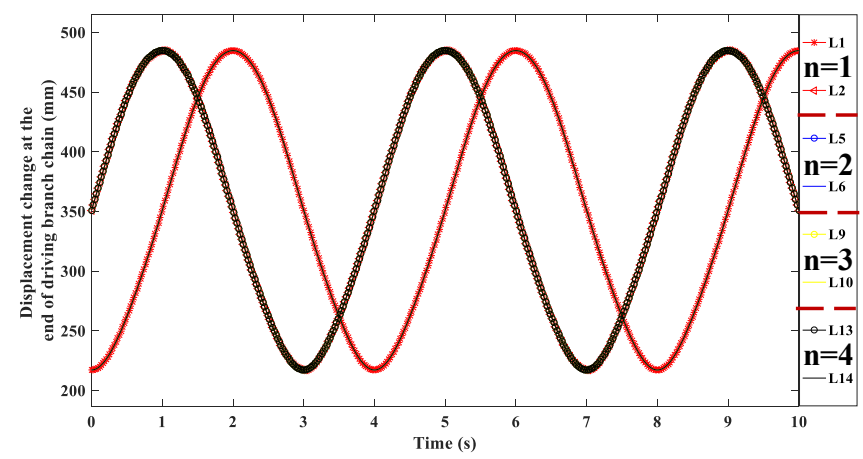

Fig.8 Simulation curve of length change of driving branch chains based on the 4-SPS/U four-level rigid trunk mechanism

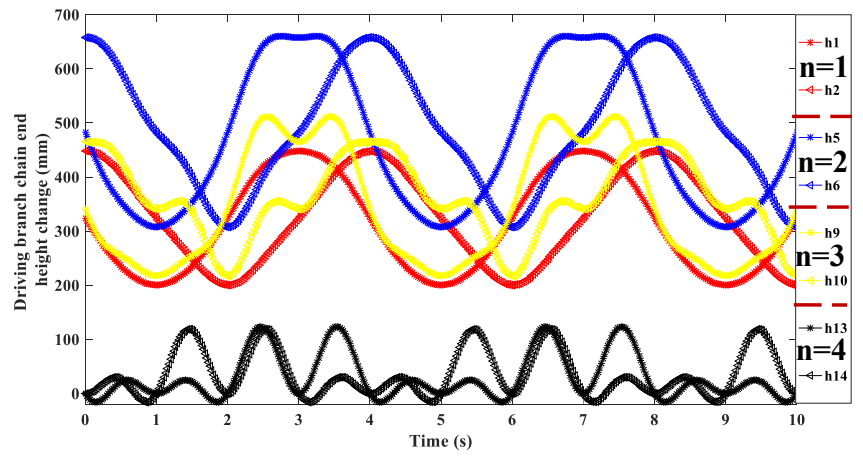

Fig.9 Simulation curve of the height change of end of driving branch chains based on the 4-SPS/U four-level rigid trunk mechanism

It can be seen from Fig. 8 that the length changes of the two adjacent chains in the nth level of the four-level trunk mechanism are overlapped together, which indicates that each level of the trunk mechanism corresponds to the same driving branch chain under the same driving function. The variation of the length of the two adjacent driving chains in the nth level is the same with time, which is in accordance with the same design principle of the 4-SPS/Ubased four-level rigid trunk mechanism. As can be seen from Fig.9, under the condition that the lengths of the two adjacent driving chains in the nth level of the trunk mechanism vary equally, the heights of the two adjacent driving chains in the Z-axis direction of each level of the trunk mechanism are higher and then lower as the number of levels increases. This indicates that the trunk mechanism can produce arc-shaped bending, and expand the end range of motion as the number of levels increases. 


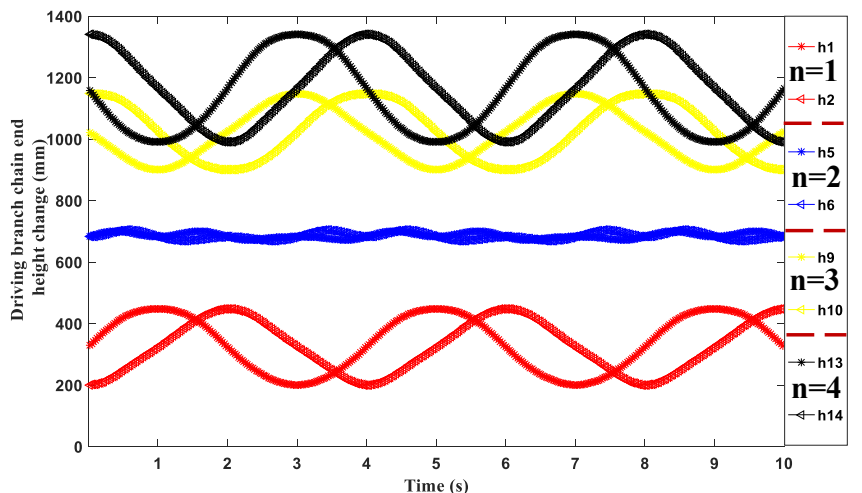

Fig.10 Simulation curve of the height change of end of driving branch chains based on the 4-SPS/U four-level rigid trunk

mechanism

As shown in Fig. 10, the driving function of the second level of the trunk mechanism is changed to the opposite direction. Comparing with Fig.9, the end heights of the two adjacent driving branches of the third and fourth levels of the trunk mechanism become higher. It is shown that by changing the end motion state of the nth level of the trunk mechanism, it is possible to achieve a variety of changes in the attitude of the trunk mechanism.

From Fig. 9, it can be found that the height curves of the two adjacent driven chains at level 1 are relatively smooth when they reach the limit position, while the height curves at level 2 start to undulate at the limit position, further increase at level 3, and are most prominent at level 4. This indicates that there is inertia in the trunk mechanism when two adjacent chains of the nth level are driven under the same driving function, and it increases with the increase of the number of levels in the trunk mechanism. From Fig. 10, we can find that the height change curve of the nth level of the trunk mechanism does not show any fluctuation, which indicates that the trunk mechanism can reduce the effect of inertia by changing the different motion states of each level of the drive chain. The undulation change data in Fig.9 shows that the undulation is very small, which indicates that the 4-SPS/U-based four-level rigid trunk mechanism has good stiffness performance and can overcome the large inertia error.

Similarly, the velocity and acceleration curves in the Z-axis direction of the 4-SPS/U-based four-level rigid trunk mechanism were obtained by simulating Eqs. (21) and (23) using MATLAB as shown in Fig. 11 and 12.

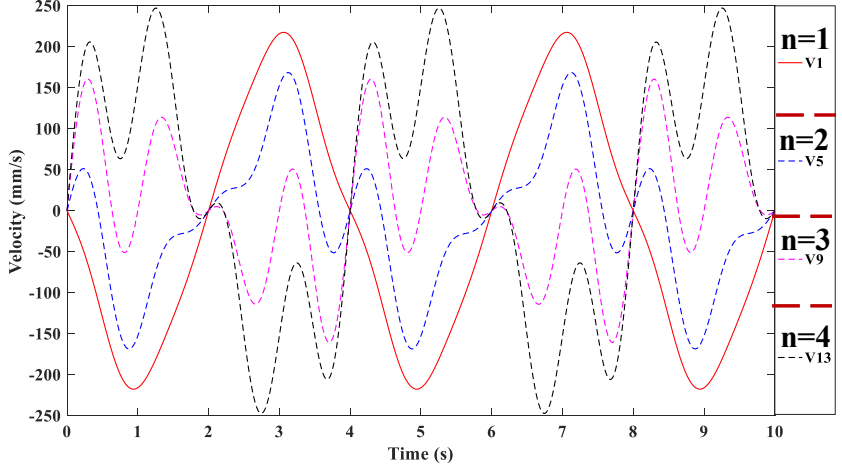

(a) the velocity of driving branch chains $1,5,9$ and 13 in the trunk joint mechanism

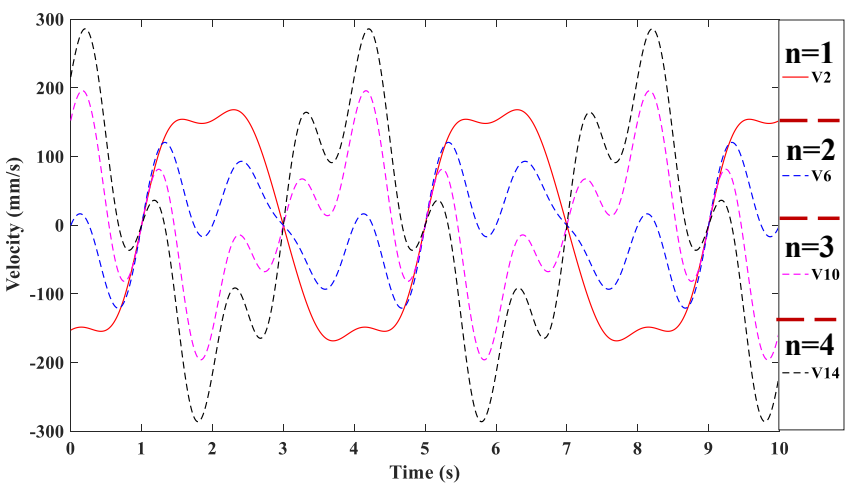

(b) the velocity of driving branch chains 2, 6, 10 and 14 in the trunk joint mechanism

Fig.11 Velocity simulation curve of two adjacent driving branch chains in nth level of four-level trunk mechanism

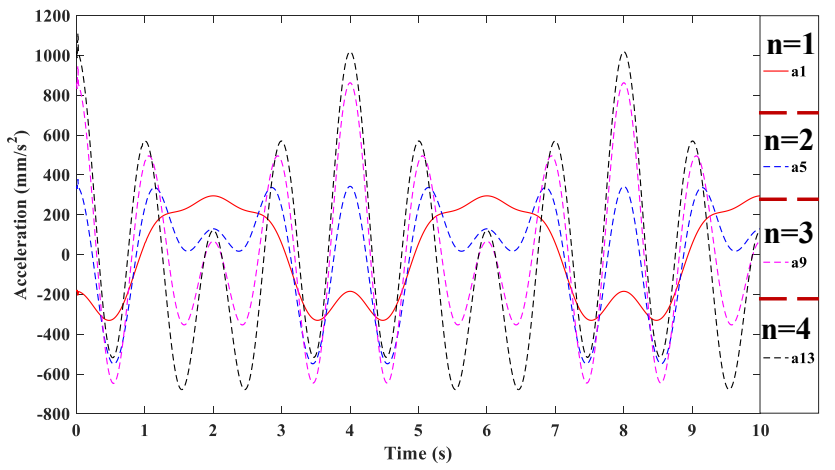

(a) the acceleration of driving branch chains 1, 5, 9 and 13 in the trunk joint mechanism

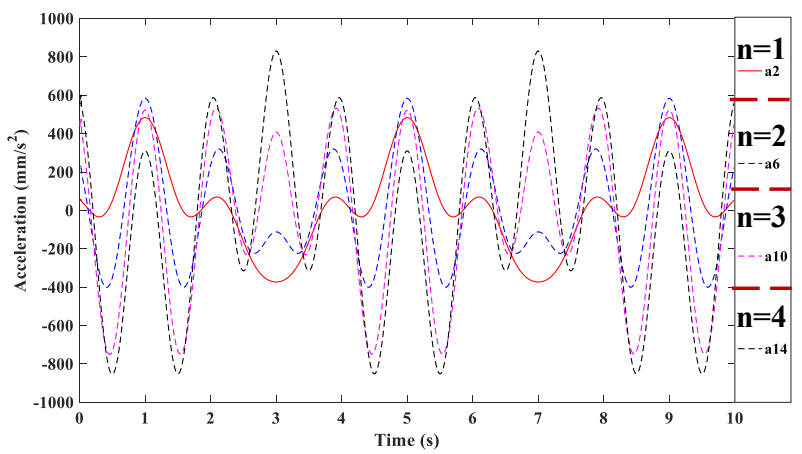


(b) the acceleration of driving branch chains 2, 6,10 and 14 in the trunk joint mechanism

Fig.12 Acceleration simulation curve of two adjacent driving branch chains in the nth level of four-level trunk mechanism

\section{Numerical examples}

In order to verify the correct kinematic performance of the 4-SPS/U-based four-level rigid trunk mechanism, as shown in Fig. 13(a), an experimental prototype platform of this mechanism was built in this thesis. As shown in Fig. 13(b), the experimental prototype works on the principle of closed-loop control of the motion formed by the STM32F103 control board with attitude sensors (1-5) and drive motors in the driving branch chain (1-16). Their $\theta_{1,1}$

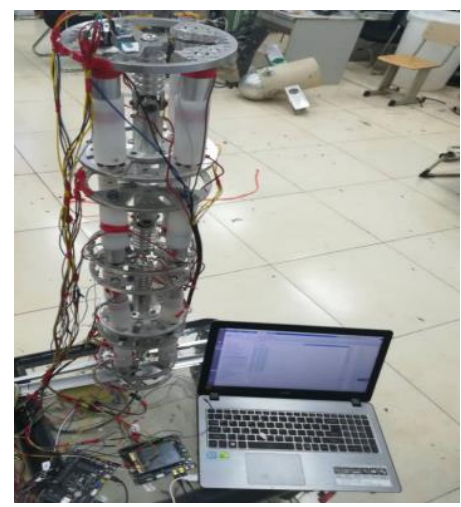

(a)Experimental prototype platform and $\theta_{1,2}$ are rotated around the $\mathrm{X}$ and $\mathrm{Y}$ axes of attitude sensor-1 by controlling attitude sensor-2; $\theta_{2,1}$ and $\theta_{2,2}$ are rotated around the $\mathrm{X}$ and $\mathrm{Y}$ axes of attitude sensor- 2 by controlling attitude sensor-3; $\theta_{3,1}$ and $\theta_{3,2}$ are rotated around the $\mathrm{X}$ and $\mathrm{Y}$ axes of attitude sensor-3 by controlling attitude sensor-4; and $\theta_{4,1}$ and $\theta_{4,2}$ are rotated around the $X$ and $\mathrm{Y}$ axes of attitude sensor- 4 by controlling attitude sensor-5. The attitude sensors- 6 are placed at the end and middle of the two adjacent drive chains of the nth level of the trunk mechanism to collect and process the displacement, height, velocity and acceleration variation data of the relevant drive chains.

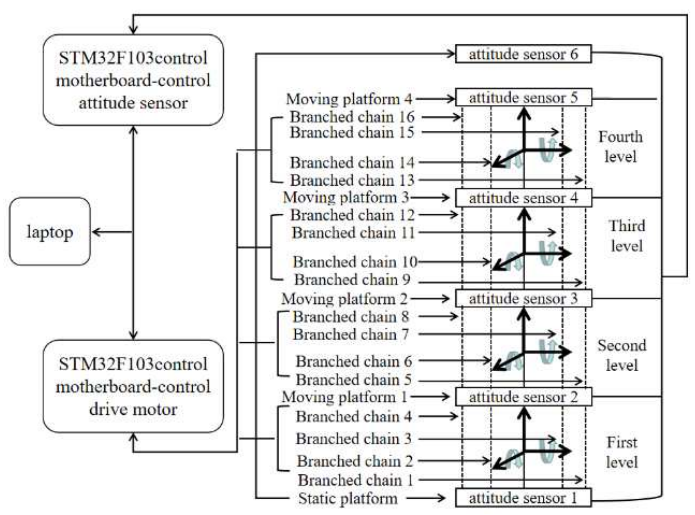

(b) Diagram of prototype operating principle

Fig 13 Experimental prototype of 4-SPS/U four-level rigid trunk mechanism

As shown in Fig. 14, the motion of the experimental prototype is controlled by the drive motors of each of the four levels corresponding to the same driving branch chain in the same direction of the drive function, and the screenshot of the experimental motion is as follows:

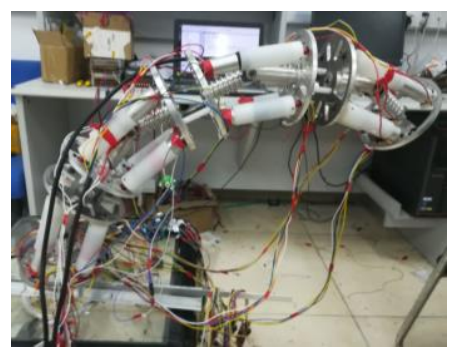

$0 \mathrm{~S}$

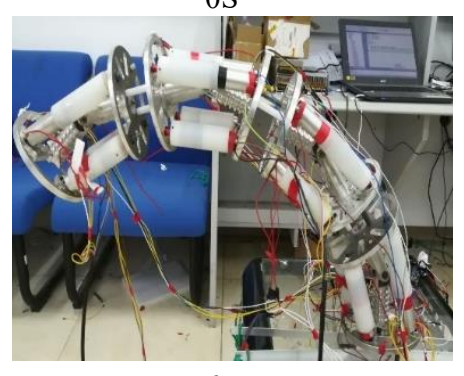

$6 \mathrm{~S}$

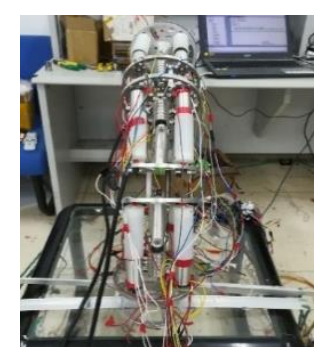

$3 \mathrm{~S}$

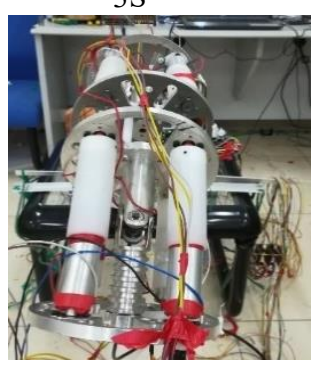

$10 \mathrm{~S}$
Fig. 14 The bending motion of experimental prototype

The motion state of the experimental prototype from 0 to $10 \mathrm{~s}$ in Fig. 14 verifies that the trunk mechanism increases the bending range of motion as the number of trunk levels increases, which is consistent with the above theoretical motion simulation motion law. As shown in Fig.15, the trunk mechanism of the second of the four levels of the experimental prototype was controlled to move in the direction of the opposite drive function of the drive motor corresponding to the same drive chain as the other three levels, and the screenshot of the experimental motion process is as follows:

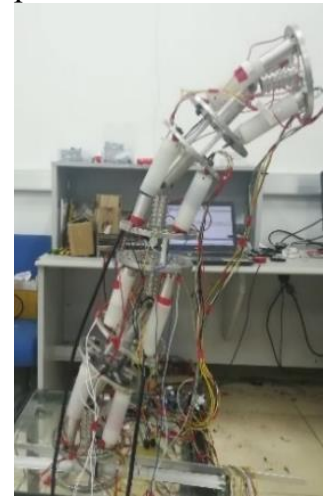

$0 \mathrm{~S}$

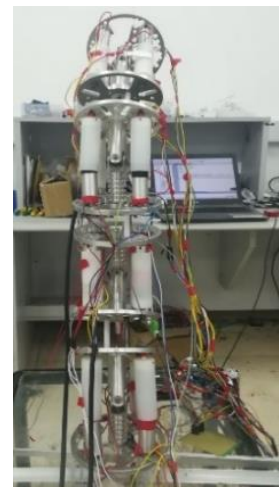

$3 \mathrm{~S}$ 


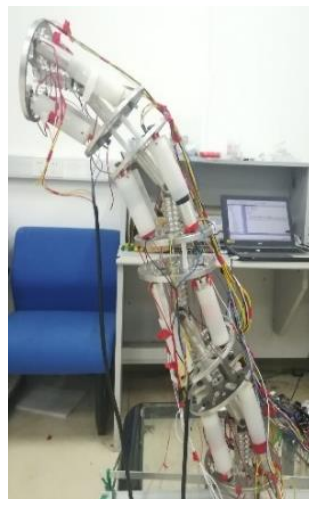

$6 \mathrm{~S}$

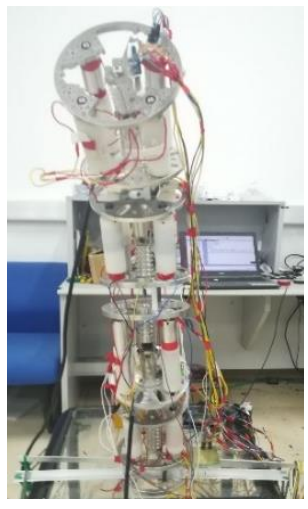

$10 \mathrm{~S}$
Fig.15 The bending motion of experimental prototype

It can be seen that the end positions of each of the four levels of the experimental prototype in Fig. 14 are: the highest end of the third level, followed by the second level, and the lowest is the first level. Comparing with the motion state from 0 to 10s in Fig. 15, the highest end of the fourth level, followed by the third level, and the lowest is the first level in Fig. 15.Therefore, it is demonstrated that the flexibility of robot posture adjustment can be improved by adjusting the end motion state of the nth level of the trunk mechanism to meet the variation of trunk mechanism posture.The data related to the displacement length, end height, velocity and acceleration variation of the nth adjacent two drive branches of the four levels of the trunk mechanism were collected by the attitude sensor- 6 and plotted together with the theoretical simulation data as shown in Figs. 16-19, respectively.

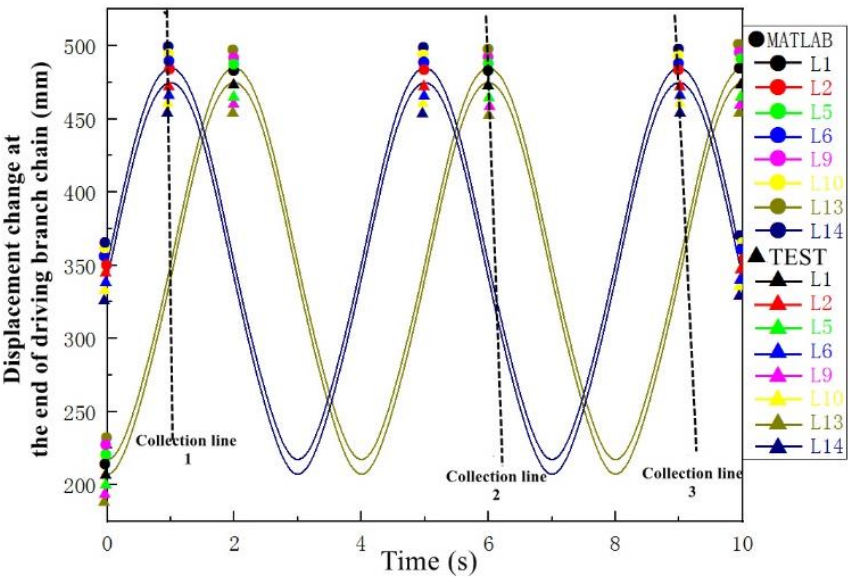

Fig.16 Displacement length theory and experimental data curve of two adjacent driving branch chains in the nth level of fourlevel trunk mechanism

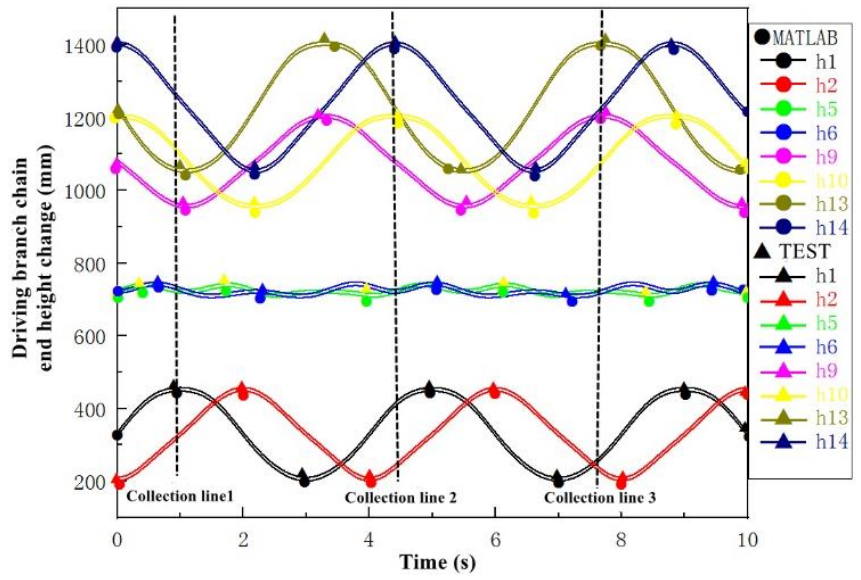

Fig.17 Height theory and experimental data curve of two adjacent driving branch chains in the nth level of four-level trunk

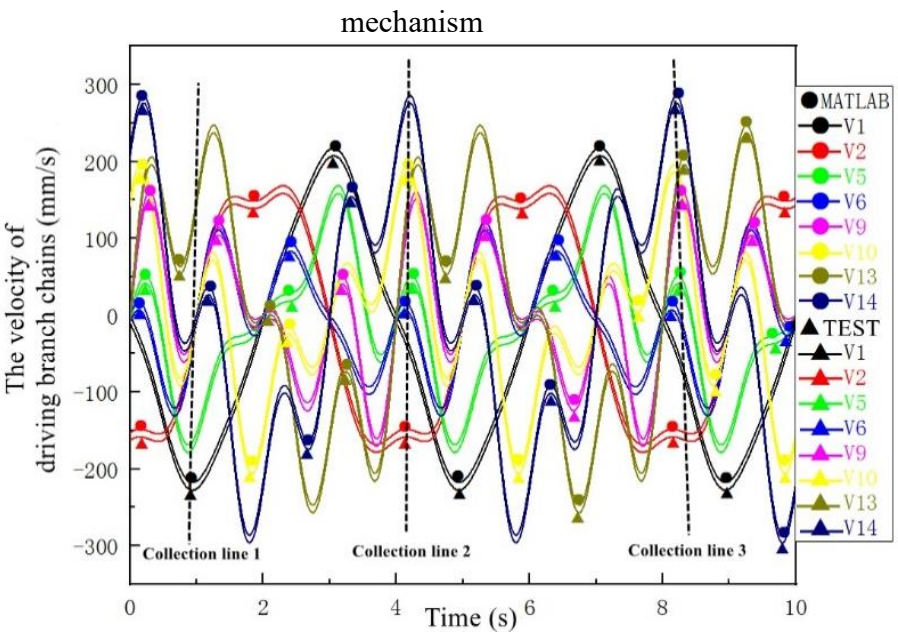

Fig.18 Velocity theory and experimental data curve of two adjacent driving branch chains in the nth level of four-level trunk

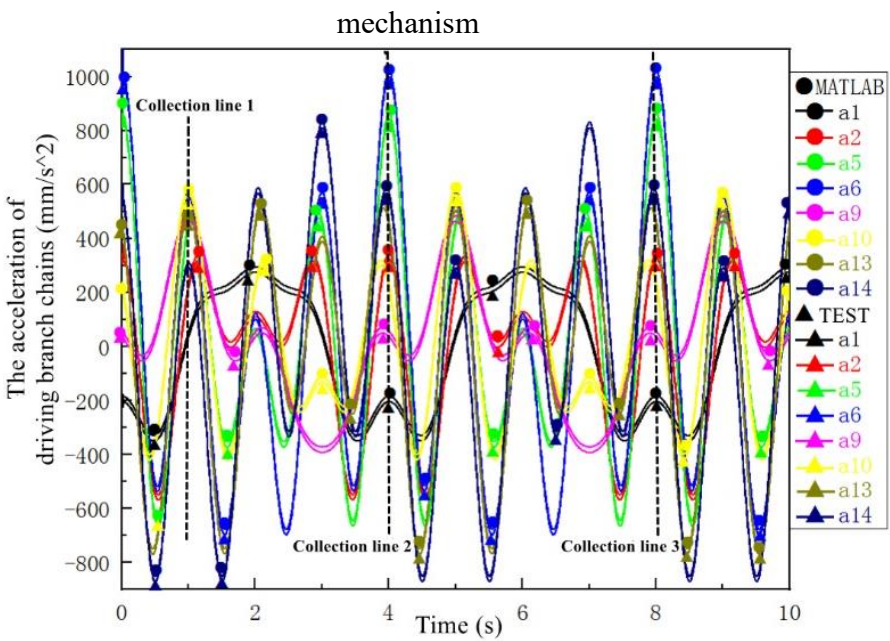

Fig.19Acceleration theory and experimental data curve of two adjacent driving branch chains in the nth level of four-level trunk mechanism 
( Here L1, h1, v1, a1 of black - - represent length, height of end, velocity and acceleration variation in MATLAB of the driving branch chain 1 in the first level of trunk mechanism, while L1, h1, v1, a1 of black - $\mathbf{\Delta}$ represent the four variables in an experimental test. L2, h2, v2, a2 of red - - represent length, height of end, velocity and acceleration variation in MATLAB of the driving branch chain 2 in the first level of trunk mechanism, while L2, h2, v2, a2 of red - $\mathbf{\Delta}$ - represent the four variables in an experimental test. L5, h5, v5, a5 of green - - represent length, height of end, velocity and acceleration variation in MATLAB of the driving branch chain 1 in the second level of trunk mechanism, while $\mathrm{L} 5$, h5, v5, a5 of green - $\Delta$ - represent the four variables in an experimental test. L6, h6, v6, a6 of blue - represent length, height of end, velocity and acceleration variation in MATLAB of the driving branch chain 2 in the second level of trunk mechanism, while L6, h6, v6, a6 of blue - $\Delta$-represent the four variables in an experimental test. L9, h9, v9, a9 of rose red - $\bullet$ - represent length, height of end, velocity and acceleration variation in MATLAB of the driving branch chain 1 in the third level of trunk mechanism, while L9, h9, v9, a9 of rose red - $\Delta$ - represent the four variables in an experimental test. L10, h10, v10, a10 of yellow - represent length, height of end, velocity and acceleration variation in MATLAB of the driving branch chain 2 in the third level of trunk mechanism, while L10, h10, v10, a10 of yellow $\triangle$ represent the four variables in an experimental test. L13, h13, v13, a13 of dark yellow -•represent length, height of end, velocity and acceleration variation in MATLAB of the driving branch chain 1 in the fourth level of trunk mechanism, while L13, h13, v13, a13 of dark yellow - $\mathbf{\Delta}$ - represent the four variables in an experimental test. L14, h14, v14, a14 of navy blue - - represent length, height of end, velocity and acceleration variation in MATLAB of the driving branch chain 2 in the fourth level of trunk mechanism, while L14, h14, v14, a14 of navy blue - $\boldsymbol{\Delta}$ - represent the four variables in an experimental test. )

From Figs. 16-19, it can be seen that the theoretical and experimental data curves of the 4-SPS/U-based four-level trunk mechanism for the drive branch displacement length, end height, velocity and acceleration in MATLAB software almost coincide exactly. To further express the error rate of comparing the theoretical data with the experimental data, 24 data points (at the intersection of the black dashed line and the curve) were randomly taken in three places in Figs. 16-19 to form the data tables of comparison displacement length, comparison height, comparison velocity, and comparison acceleration (as shown in Table 1). The contrast error rate is expressed as follows: Contrast error $=\frac{\sum_{g=1}^{24}(\| \text { Theoretical data }\|-\| \text { Experimental data } \|)}{\sum_{g=1}^{24}(\| \text { Theoretical data } \|)}$

It can be seen from Table 1 that the coincidence degree of the theoretical and experimental data curves in MATLAB software is $99.2 \%, 99.8 \%, 99.5 \%, 99.1 \%(1$ minus the contrast error rate) for the drive branch displacement length, end height, velocity and acceleration based on the 4-SPS/U type four-level trunk mechanism. Therefore, the correctness and reliability of the kinematic theory derivation in this paper are verified. Its error rate during the motion may be caused by the mutual frictional interference between the upper and lower mobile sleeves of the motion support chain, between the ball hinge and the ball hinge seat, and the intermediate restraint support chain in the experimental prototype.

Table 1. Error of comparison between theoretical data and experimental data

\begin{tabular}{|c|c|c|c|c|c|c|c|c|c|c|c|c|c|c|}
\hline Title & Data Type & & & & & & lom cc & ction & 4 data & & & & & $\begin{array}{c}\text { Contrast } \\
\text { Error }\end{array}$ \\
\hline \multirow{4}{*}{$\begin{array}{c}\text { Contrast } \\
\text { displacement } \\
\text { length } \\
\mathrm{L}(\mathrm{mm})\end{array}$} & Theoretical & 476 & 476 & 476 & 476 & 349 & 349 & 349 & 349 & 476 & 476 & 476 & 476 & \multirow{4}{*}{$\begin{array}{l}0.8 \\
(\%)\end{array}$} \\
\hline & data & 349 & 349 & 349 & 349 & 476 & 476 & 476 & 476 & 349 & 349 & 349 & 349 & \\
\hline & \multirow{2}{*}{$\begin{array}{l}\text { Experimental } \\
\text { data }\end{array}$} & $\begin{array}{c}475 \\
.5\end{array}$ & 475.5 & $\begin{array}{c}475 . \\
5\end{array}$ & $\begin{array}{c}475 . \\
5\end{array}$ & 348.8 & $\begin{array}{c}348 . \\
8\end{array}$ & $\begin{array}{c}348 . \\
8\end{array}$ & 348.8 & 475.5 & $\begin{array}{c}475 . \\
5\end{array}$ & 475.5 & 475.5 & \\
\hline & & $\begin{array}{c}348 \\
.8\end{array}$ & 348.8 & $\begin{array}{c}348 . \\
8\end{array}$ & $\begin{array}{c}348 . \\
8\end{array}$ & 475.5 & $\begin{array}{c}475 . \\
5\end{array}$ & $\begin{array}{c}475 . \\
5\end{array}$ & 475.5 & 348.8 & $\begin{array}{c}348 . \\
8\end{array}$ & 348.8 & 348.8 & \\
\hline $\begin{array}{l}\text { Contrast } \\
\text { height }\end{array}$ & $\begin{array}{c}\text { Theoretical } \\
\text { data }\end{array}$ & $\begin{array}{c}128 \\
5\end{array}$ & 1145 & 1084 & 992 & 706 & 703 & 485 & 301 & 1400 & $\begin{array}{c}121 \\
0\end{array}$ & 1200 & 1098 & $\begin{array}{l}0.2 \\
(\%)\end{array}$ \\
\hline
\end{tabular}




\begin{tabular}{|c|c|c|c|c|c|c|c|c|c|c|c|c|c|c|}
\hline $\mathrm{h}(\mathrm{mm})$ & & 702 & 700 & 455 & $\begin{array}{c}212 . \\
2\end{array}$ & $\begin{array}{c}1400 \\
.2\end{array}$ & $\begin{array}{c}1202 \\
.2\end{array}$ & $\begin{array}{c}1200 \\
.1\end{array}$ & 1100 & 705.5 & $\begin{array}{c}701 . \\
1\end{array}$ & 255.9 & 210.6 & \\
\hline & Experimental & $\begin{array}{l}128 \\
4.9\end{array}$ & 1144.9 & $\begin{array}{c}1083 \\
.8\end{array}$ & $\begin{array}{l}991 . \\
9\end{array}$ & 705.8 & $\begin{array}{l}702 . \\
9\end{array}$ & $\begin{array}{l}484 . \\
7\end{array}$ & 300.9 & 1399.7 & $\begin{array}{l}120 \\
9.9\end{array}$ & 1199.8 & $\begin{array}{l}1097 . \\
9\end{array}$ & \\
\hline & data & $\begin{array}{l}701 \\
.9 \\
\end{array}$ & 699.8 & $\begin{array}{c}454 . \\
8 \\
\end{array}$ & 212 & 1400 & 1202 & 1200 & 1099.9 & 705.3 & 700 & 255.8 & 210.4 & \\
\hline \multirow{4}{*}{$\begin{array}{l}\text { Contrast } \\
\text { Speed } \\
\mathrm{V}(\mathrm{mm} / \mathrm{s})\end{array}$} & \multirow{2}{*}{$\begin{array}{c}\text { Theoretical } \\
\text { data }\end{array}$} & $\begin{array}{c}140 \\
.1\end{array}$ & -2.2 & -2.2 & -2.2 & -2 & -2.2 & $\begin{array}{c}- \\
163 . \\
3\end{array}$ & -225.2 & 295.1 & $\begin{array}{c}202 . \\
9\end{array}$ & 148.3 & 5.3 & \multirow{4}{*}{$\begin{array}{l}0.5 \\
(\%)\end{array}$} \\
\hline & & 1.2 & 0 & -1.2 & -50.3 & 299.9 & 202 & $\begin{array}{c}170 . \\
2\end{array}$ & 50 & 3.3 & 1.2 & -7.8 & $\begin{array}{l}-50.3 \\
\end{array}$ & \\
\hline & \multirow{2}{*}{$\begin{array}{c}\text { Experimental } \\
\text { data }\end{array}$} & 140 & -2 & -2.1 & -2.2 & -1.9 & -2.1 & -160 & -225 & 294.8 & $\begin{array}{c}202 . \\
6\end{array}$ & 148.2 & 5.1 & \\
\hline & & 1 & 0 & -1 & -50 & 297.7 & $\begin{array}{c}201 . \\
8\end{array}$ & 170 & 49.8 & 3.1 & 1 & -7.6 & -50 & \\
\hline \multirow{4}{*}{$\begin{array}{c}\text { Contrast } \\
\text { acceleration } \\
\mathrm{a}\left(\mathrm{mm} / \mathrm{s}^{\wedge} 2\right)\end{array}$} & \multirow{2}{*}{$\begin{array}{c}\text { Theoretical } \\
\text { data }\end{array}$} & 601 & 580.3 & $\begin{array}{c}581 . \\
2\end{array}$ & 300 & 299.1 & $\begin{array}{c}101 . \\
6\end{array}$ & 98.5 & 50.2 & 100.3 & $\begin{array}{c}900 . \\
2\end{array}$ & 612 & 400 & \multirow{4}{*}{$\begin{array}{l}0.9 \\
(\%)\end{array}$} \\
\hline & & $\begin{array}{c}390 \\
.7\end{array}$ & 99.7 & 0 & $\begin{array}{c}- \\
190 . \\
2 \\
\end{array}$ & 100.4 & $\begin{array}{c}963 . \\
2\end{array}$ & $\begin{array}{c}600 . \\
3\end{array}$ & 344.3 & 300.2 & 100 & 89.7 & $\begin{array}{c}- \\
181.6\end{array}$ & \\
\hline & \multirow{2}{*}{$\begin{array}{c}\text { Experimental } \\
\text { data }\end{array}$} & $\begin{array}{c}599 \\
.7\end{array}$ & 580 & $\begin{array}{c}579 . \\
9\end{array}$ & $\begin{array}{c}299 . \\
8\end{array}$ & 298.8 & $\begin{array}{c}101 . \\
2\end{array}$ & 98.2 & 50 & 999.9 & $\begin{array}{c}899 . \\
9\end{array}$ & 611.9 & 399.7 & \\
\hline & & 390 & 99.4 & -0.2 & -190 & 100.2 & 963 & 600 & 344 & 299.9 & 99.8 & 89.5 & -181 & \\
\hline
\end{tabular}

\section{Conclusions}

(1) In this thesis, a 4-SPS/U type four-level rigid trunk mechanism is innovatively designed by Basing on the characteristics of the four-stage series connection, using SPS as the driving branch and U as the intermediate restrained driven branch.

(2) The screw theory is used to verify that the trunk mechanism can achieve four two degrees of freedom rotation, so that the multi-motor hexapod mobile robot can achieve multi-level and multidimensional motion flexibility through the nth level of attitude change in the trunk mechanism, thus improving the reliability of the robot in walking, water propulsion, climbing, rolling and other multimotor attitude adjustment in unknown complex environments.

(3) The closed vector method has been applied for constructing its inverse kinematics solution, and the velocity and acceleration motion models as well as the Jacobian matrix are established by time derivative of the inverse kinematics solution.

(4) Based on the workspace constraint equation of the trunk mechanism, the numerical search method is adopted in MALTAB to simulate its workspace, which demonstrates that the big workspace, flexibility and posture diversity of the trunk mechanism allow the hexapod mobile robot to adjust its multifarious moving postures in various environments.

(5) It is verified that the kinematics theory of the trunk mechanism is correct and reliable through the experimental data of the experimental prototype, which provides reference value for the future research on the kinematics performance of he multimotion mode hexapod mobile robot's trunk mechanism.

\section{Declaration}

\section{Acknowledgements}

The authors sincerely thanks to Professor Jizhuang Fan and Mr. Gangfeng Liu of Harbin Institute of Technology for his critical discussion and reading during manuscript preparation.

\section{Funding}

Supported by National Natural Science Foundation of China (Grant No.U2013214), Support by SelfPlanned Task of State Key Laboratory of Robotics and System (HIT) （NO. SKLRS202001A03 )

\section{Availability of data and materials}

The datasets supporting the conclusions of this article are included within the article. 


\section{Authors' contributions}

The author' contributions are as follows: YitaoPan and ShuqiWang were in charge of the whole trial; YitaoPan wrote the manuscript; YitaoPan and ShuqiWang assisted with sampling and laboratory analyses.

\section{Competing interests}

The authors declare no competing financial interests.

\section{Consent for publication}

Not applicable

\section{Ethics approval and consent to participate}

Not applicable

\section{References}

[1] DENG Le, ZHAO Lili, et al. Obstacle surmounting analysis of robot for under-mine rescue[J]. Journal of Henan Polytechnic University (Natural Science), 2011, 30(5): 568- 570.

[2] YUAN Xin, LI Qing, ZHANG Hao, et al. ORBSLAM Research of Snake-like Rescue Robot[J]. Science Technology and Engineering, 2016, 16(31): 230-233

[3] LI Zhihai. Study on wheel leg hybrid wall climbing robot and its key technology[D]. Harbin: Harbin Institute of Technology, 2010.

[4] Kim Y S, Jung G P, Kim H, et al. Wheel Transformer: AWheel-Leg Hybrid Robot with Passive Transformable Wheels[J]. IEEE TranSactions on Robotics, 2017, 30(6): 1487-1498.

[5] TIAN Mu. Research on the kinematics and dynamics of wheel-tracked search and rescue robot mobile platform[D]. Jiaozuo: Henan polytechnic University, 2016.

[6] Phipps C C, Minor M A. Introducing the hex-aball,a hybrid locomotion terrain adaptive walking and rolling $\operatorname{robot}[\mathrm{C}]$. The 8th International Conference on Climbing and Walking Robots, London, 2005. 525-532.

[7] HUANG Hulin. A 3-DOF Series-parallel Structure Torso Design in Humanoid Robots[D]. Beijing: Beijing Institute of Technology.

[8] Kanehiro F, Kaneko K, Fujiwara K, et al. The firsthumanoid robot that has the same size as a human and that can lie down and get up[C]. IEEE
International Conference on Robotics Automation. Taipei, 2003. 1633-1639.

[9] Ogura Y, Aikawa H, Shimomura K, et al. Development of a New Humanoid Robot WABIAN2[C]. IEEE International Conference on Robotics and Automation. Taipei, 2006. 76-81.

[10] Metta G, Sandini G, Vernon D, et al. The i Cub humanoid robot: an open platform for research in embodied cognition[C]. The 8th Workshop on Performance Metrics for Intelligent Systems. Gaithersburg, 2008. 50-56.

[11] Beira R, Lopes M, Praga M, et al. Design of the robot-cub ( I Cub) head[C]. IEEE International Conference on Robotics and Biominetics, Orlando, 2006. 94-100.

[12] Pan Y T, Chen Y, Li L. Analysis of kinematic dexterity and stiffness performance based on Spring's wire-driven 4-SPS/U rigid-flexible parallel trunk joint mechanism[J]. International Journal of Structural Integrity, 2019, 10(6): 850-867.

[13] LI Jianfeng, LI Shicai, TAO Chunjing, et al. Parallel 2-UPS/RRR Ankle Rehabilitation Mechanism and Kinematic Performance Analysis[J]. Robot, 2016, 38(2): 145-153.

[14] Zhu C, Liu X, Liu W. Research on structural optimization of 3-TPT parallel mechanism based on stiffness characteristics[J]. Mechanics Based Design of Structures and Machines, 2019: 1-15.

[15] Portman V T, Chapsky V S, Shneora Y. Workspace of parallel kinematics machines with minimum stiffness limits: collinear stiffness value based approach $[\mathrm{J}]$. Mechanism and Machine Theory, 2012, 49: 67-86.

[16] Khalid A, Mekid S. Design synthesis of a three legged SPS parallel manipulator[C]. The 36th International MATADOR Conference, London, 2010, 169-173.

[17] Khalid A, Mekid S. Intelligent spherical joints based tri-actuated spatial parallel manipulator for precision applications[J]. Robotics and ComputerIntegrated Manufacturing, 2018, 54: 173-184.

[18] Khalid A, Mekid S. Jacobian inversion analysis and extraction of dexterous workspace in PKMs[C]. The 35th International MATADOR Conference, London, 2007, 293-296.

[19] CHEN Xiulong, CHEN Linlin, LIANG Xiaoxia. Kinematics and Workspace Analysis of a Novel 4- 
DOF Redundant Actuation Parallel Mechanism[J]. Transactions of the Chinese Society for Agricultural Machinery, 2014, 8(45): 307-313.

[20] XIE Zhedong, JIA Yuxuan, SHAO Qi, et al. Analysis the working space and kinematics of the micro 3-PSP parallel mechanism [J]. 2018, 4(40): 915-922.

[21] HUANG Zhen, ZENG Daxin. Calculation of degrees of freedom of mechanism: principles and methods [M]. Beijing: Higher Education Press, 2016: 1-273.

[22] Zang H, Fang H. Performance analysis of a redundantly actuated parallel manipulator with suitable constraint branch[J]. Journal of Beijing Jiaotong University, 2018. 42(1): 134-138.

[23] Quintero-Riaza H F, Mej'ia-Calderón L A, D'1az-Rodr'iguez M. Synthesis of planar parallel manipulators including dexterity, force transmission and stiffness index[J]. Mechanics Based Design of Structures and Machines, 2019, 47(6): 680-702.

[24] Zarkandi S. Kinematics and singularity analysis of a parallel manipulator with three rotational and one translational DOFs[J]. Mechanics based design of structures and machines, 2011, 39(3): 392-407.

[25] Castelli G, Ottaviano E, Ceccarelli M. A fairly general algorithm to evaluate workspace characteristics of serial and parallel manipulators[J]. Mechanics based design of structures and machines, 2008, 36(1): 14-33. 


\section{Supplementary Files}

This is a list of supplementary files associated with this preprint. Click to download.

- Experimentrelatedvideos.rar 